\title{
The complete mitochondrial genome of the house dust mite Dermatophagoides pteronyssinus (Trouessart): a novel gene arrangement among arthropods
}

\author{
Wannes Dermauw*1, Thomas Van Leeuwen ${ }^{1}$, Bartel Vanholme ${ }^{2,3}$ and \\ Luc Tirry ${ }^{1}$
}

Address: ${ }^{1}$ Department of Crop Protection, Faculty of Bioscience Engineering, Ghent University, Coupure links 653, B-9000, Ghent, Belgium, 2Department of Molecular Biotechnology, Faculty of Bioscience Engineering, Ghent University, Coupure links 653, B-9000, Ghent, Belgium and 3VIB Department of Plant Systems Biology, Ghent University, Technologiepark 927, B-9052, Ghent, Belgium

Email: Wannes Dermauw* - wannes.dermauw@ugent.be; Thomas Van Leeuwen - thomas.vanleeuwen@ugent.be; Bartel Vanholme - bahol@PSB.ugent.be; Luc Tirry - luc.tirry@ugent.be

* Corresponding author

Published: 13 March 2009

BMC Genomics 2009, 10:107 doi:10.1186/147|-2164-10-107
Received: 31 October 2008

Accepted: 13 March 2009

This article is available from: http://www.biomedcentral.com/147I-2/64/10/107

(C) 2009 Dermauw et al; licensee BioMed Central Ltd.

This is an Open Access article distributed under the terms of the Creative Commons Attribution License (http://creativecommons.org/licenses/by/2.0), which permits unrestricted use, distribution, and reproduction in any medium, provided the original work is properly cited.

\begin{abstract}
Background: The apparent scarcity of available sequence data has greatly impeded evolutionary studies in Acari (mites and ticks). This subclass encompasses over 48,000 species and forms the largest group within the Arachnida. Although mitochondrial genomes are widely utilised for phylogenetic and population genetic studies, only 20 mitochondrial genomes of Acari have been determined, of which only one belongs to the diverse order of the Sarcoptiformes. In this study, we describe the mitochondrial genome of the European house dust mite Dermatophagoides pteronyssinus, the most important member of this largely neglected group.

Results: The mitochondrial genome of $D$. pteronyssinus is a circular DNA molecule of 14,203 bp. It contains the complete set of 37 genes (13 protein coding genes, 2 rRNA genes and 22 tRNA genes), usually present in metazoan mitochondrial genomes. The mitochondrial gene order differs considerably from that of other Acari mitochondrial genomes. Compared to the mitochondrial genome of Limulus polyphemus, considered as the ancestral arthropod pattern, only II of the 38 gene boundaries are conserved. The majority strand has a $72.6 \%$ AT-content but a GC-skew of 0.194 . This skew is the reverse of that normally observed for typical animal mitochondrial genomes. A microsatellite was detected in a large non-coding region ( $286 \mathrm{bp})$, which probably functions as the control region. Almost all tRNA genes lack a T-arm, provoking the formation of canonical cloverleaf tRNA-structures, and both rRNA genes are considerably reduced in size. Finally, the genomic sequence was used to perform a phylogenetic study. Both maximum likelihood and Bayesian inference analysis clustered $D$. pteronyssinus with Steganacarus magnus, forming a sistergroup of the Trombidiformes.

Conclusion: Although the mitochondrial genome of $D$. pteronyssinus shares different features with previously characterised Acari mitochondrial genomes, it is unique in many ways. Gene order is extremely rearranged and represents a new pattern within the Acari. Both tRNAs and rRNAs are truncated, corroborating the theory of the functional co-evolution of these molecules. Furthermore, the strong and reversed GC- and AT-skews suggest the inversion of the control region as an evolutionary event. Finally, phylogenetic analysis using concatenated $\mathrm{mt}$ gene sequences succeeded in recovering Acari relationships concordant with traditional views of phylogeny of Acari.
\end{abstract}




\section{Background}

Approximately 48,000 mite and tick species (Arthropoda: Chelicerata: Arachnida: Acari) $[1,2]$ have been described to this day. Since the number of undescribed species is thought to be twenty-fold higher, this subclass is by far the most species-rich group among the Arachnida [2]. Acari diversified 400 million years ago and currently three major lineages are recognised: Opilioacariformes, Acariformes and Parasitiformes [2,3]. The Acariformes comprise two major groups, the Trombidiformes and Sarcoptiformes $[2,4]$. Two of the most prominent members of the Sarcoptiformes are the European house dust mite Dermatophagoides pteronyssinus (Trouessart, 1897) and the American house dust mite Dermatophagoides farinae (Hughes, 1961), both belonging to the family of the Pyroglyphidae (cohort Astigmata). Pyroglyphid mites are typical inhabitants of animal nests. In the human environment, they are mainly found in upholstery, textile floor covers and beddings, where they primarily feed on the skin scale fraction in house dust [5]. About 40 years ago, house dust mites were first recognized as one of the major sources of allergens in house dust [6]. The allergenic proteins are found in high concentrations in mite faeces, which, after drying and pulverizing, become airborne and can be inhaled. The presence of these allergens in sensitive persons is able to cause diseases like asthma, dermatitis and rhinitis $[7,8]$. In countries with a temperate climate, 6 to 35 per cent of the population is sensitive to house dust mite-derived allergens [9].

Complete mitochondrial (mt) genome sequences are becoming increasingly important for effective evolutionary and population studies. Mt genome sequences are not only more informative than shorter sequences of individual genes, they also provide sets of genome-level characters, such as the relative position of different genes, RNA secondary structures and modes of control of replication and transcription [10-13]. However, the applicability of mt genomes as a marker of highly divergent lineages is still controversial $[14,15]$ and remains to be elucidated [16]. In addition, unravelling mt genomes can be of economic importance as well, since several chemical classes of pesticides target mt proteins. Well-known acaricides like acequinocyl and fluacrypyrim affect mt electron transport through the inhibition of the mt encoded cytochrome b in complex III [17]. Also, the economically important class of METI (Mitochondrial Electron Transfer Inhibitors)-acaricides target the mt complex I, although their exact molecular target has not yet been elucidated. Recently, resistance to the acaricide bifenazate was shown to be caused by mutations in the mt encoded cytochrome $\mathrm{b}$ and to have evolved rapidly through a short stage of $\mathrm{mt}$ heteroplasmy [18].
At present, the mt genomes of 20 species belonging to the Acari are available at NCBI ([19], status January 10, 2009). Most of the submitted sequences have the typical features of metazoan mt genomes. They are circular, between 13 and $20 \mathrm{~kb}$ in length, contain a coding region with 37 genes (22 tRNAs, 2 rRNAs and 13 protein coding genes) and a relatively small non-coding region. The latter is mostly AT-rich and fulfils a role in the initiation of replication and transcription $[20,21]$. Compared to this typical configuration, the mt genomes of Steganacarus magnus, Metaseiulus occidentalis and Leptotrombidium pallidum show some abnormal features. S. magnus lacks 16 of the 22 tRNAs normally present in $\mathrm{mt}$ genomes [22]. M. occidentalis has a unusually large $\mathrm{mt}$ genome $(24.9 \mathrm{~kb})$ resulting from a duplication event of a large fragment of the codon region. Despite its large size, genes coding for nad6 and nad3 were not found during the initial annotation process [23]. L. pallidum on the other hand has $38 \mathrm{mt}$ genes due to a duplication of the 16S-rRNA [24].

In this study, we analyse the complete mt genome of a member of the Sarcoptiformes, the European house dust mite D. pteronyssinus, after obtaining the complete sequence using a long PCR approach.

\section{Results and discussion Genome organisation}

The mt genome of $D$. pteronyssinus was amplified, using long PCR, in three overlapping fragments. The final assembled sequence was 14,203 bp [GenBank: EU884425; Fig. 1], making it the fifth smallest sequenced genome within the Acari. Only the mt genomes of Tetranychus urticae $(13,103 \mathrm{bp})$, Leptotrombidium akamushi (13,698 bp), Leptotrombidium deliense (13,731 bp) and $S$. magnus (13,818 bp) are smaller (Table 1 [25-27]). As nonspecific amplification artefacts and incomplete coverage of genes are well-known drawbacks of a PCR approach [28], we checked the genome size by restriction digest on rolling circle amplified mtDNA (Fig. 2). This approach confirmed the sequence size, considering that the relative mobility of mtDNA restriction fragments can show slight (5-12\%) deviations compared to their sequence length [29]. The mt genome of D. pteronyssinus is the first $\mathrm{mt}$ sequence of a mite belonging to the Astigmata and is together with the mt genome of $S$. magnus the only representative from the order of the Sarcoptiformes. Adding this genome to the database resulted in 21 publicly available Acari mtDNA sequences. Twelve belong to species in the superorder of the Parasitiformes whereas nine among which D. pteronyssinus - belong to species in the superorder of the Acariformes.

All 37 genes present in a standard metazoan mt genome could be identified (Fig. 1). Gene overlap exists between $\operatorname{trnD} / \operatorname{atp} 8$ (1 bp), trnR/nad3 (17 bp), trnM/trnS 2 (12 bp), 


\begin{tabular}{|c|c|c|c|c|c|c|c|c|c|c|c|c|c|c|c|}
\hline \multirow[t]{2}{*}{ Organism $^{a}$} & \multirow[t]{2}{*}{$\mathbf{S}^{\mathrm{b}}$} & \multirow[t]{2}{*}{ Genbank acc. nr } & \multicolumn{4}{|c|}{ Complete mt genome } & \multicolumn{2}{|c|}{ mt PCG ${ }^{c}$} & \multicolumn{2}{|c|}{ I2S-rRNA } & \multicolumn{2}{|c|}{ I6S-rRNA } & \multicolumn{2}{|c|}{ Control Region(s) } & \multirow[t]{2}{*}{ Ref. e } \\
\hline & & & Length (bp) & AT\% & AT-skew $f$ & GC-skew & Length (bp) & AT\% & Lengh (bp) & AT\% & Length (bp) & AT\% & Length (bp) & AT\% & \\
\hline D. pteronyssinus & A & EU884425 & 14,203 & 72.60 & -0.199 & 0.194 & 10,826 & 71.61 & 665 & 72.93 & 1078 & 76.07 & 286 & 91.61 & this study \\
\hline Am. triguttatum & $P$ & $\underline{N C 005963}$ & 14,740 & 78.40 & -0.022 & -0.133 & 10,876 & 78.29 & 693 & 79.65 & 1199 & 81.82 & $307-307$ & $71.66-71.01$ & unpub. \\
\hline As. sp.g & A & $\underline{N C 010596}$ & 16,067 & 70.07 & 0.015 & -0.049 & 10,560 & 69.27 & 680 & 72.79 & 1047 & 76.31 & $1207-1236$ & $70.01-70.06$ & unpub. \\
\hline C. capensis & $P$ & NC 005291 & $|4,4| 8$ & 73.54 & 0.036 & -0.374 & 10,873 & 72.66 & 695 & 76.26 & 1225 & 78.29 & 342 & 71.35 & [38] \\
\hline H. flava & $P$ & NC 005292 & 14,686 & 76.91 & -0.018 & -0.116 & 10,817 & 76.65 & 699 & 78.40 & 1196 & 81.61 & $310-310$ & $66.45-66.77$ & [38] \\
\hline I. hexagonus & $P$ & NC 002010 & 14,539 & 72.66 & 0.033 & -0.366 & 10,826 & 71.13 & 705 & 78.44 & 1287 & 72.60 & 359 & 71.87 & {$[37]$} \\
\hline I. holocyclus & $P$ & $\underline{N C 005293}$ & 15,007 & 77.38 & -0.013 & -0.254 & 10,860 & 76.38 & 716 & 77.93 & 1214 & 81.55 & $352-450$ & $78.41-80.00$ & [26] \\
\hline I. persulcatus & $P$ & NC 004370 & 14,539 & 77.34 & -0.024 & -0.269 & 10,879 & 76.59 & 720 & 78.89 & 1206 & 79.77 & 352 & 77.56 & [26] \\
\hline I. uriae & $P$ & $\underline{N C} 006078$ & 15,053 & 74.79 & 0.007 & -0.328 & 10,837 & 73.75 & 712 & 78.09 & 1210 & 78.35 & $388-476$ & $77.06-74.16$ & [26] \\
\hline Le. akamushi & A & NC 007601 & 13,698 & 67.47 & -0.016 & -0.075 & 10,292 & 67.19 & 596 & 67.11 & 1026 & 72.03 & $260-262$ & $60.38-59.54$ & {$[74]$} \\
\hline Le. deliense & A & NC 007600 & $|3,73|$ & 69.95 & -0.017 & -0.058 & 10,292 & 70.06 & 602 & 70.27 & 1023 & 73.02 & $294-301$ & $62.24-61.79$ & {$[74]$} \\
\hline Le. pallidum ${ }^{h}$ & A & NC 007177 & 16,779 & 70.96 & -0.031 & -0.044 & 10,312 & 71.38 & 601 & 72.05 & 1008 & 74.90 & $537-724-736-803$ & 63.87-66.7I-66.75-66.50 & [24] \\
\hline M. occidentalisi & $P$ & NC 009093 & 24,961 & 75.97 & 0.095 & -0.291 & 10,014 & 74.38 & 742 & 81.13 & 1192 & 84.31 & $3|0-3||-3||-3| \mid$ & $79.35-79.10-79.42-78.78$ & [23] \\
\hline O. moubata & $P$ & $\underline{N C 004357}$ & 14,398 & 72.26 & 0.067 & -0.379 & 10,890 & 71.35 & 686 & 74.20 & 1212 & 76.90 & 342 & 71.64 & [38] \\
\hline O. porcinus & $P$ & NC 005820 & 14,378 & 70.98 & 0.059 & -0.355 & 10,877 & 70.11 & 691 & 74.38 & 1207 & 74.48 & 338 & 69.53 & [27] \\
\hline R. sanguineus & $P$ & NC 002074 & 14,710 & 77.96 & -0.034 & -0.098 & 10,803 & 77.96 & 687 & 79.18 & 1190 & 81.34 & 303-305 & $67.33-66.56$ & {$[37]$} \\
\hline S. magnus & A & $\underline{N C} 011574$ & $13,8 \mid 8$ & 74.59 & -0.020 & -0.037 & 10,560 & 74.44 & 609 & 74.38 & 992 & 74.38 & 1018 & 75.66 & [22] \\
\hline T. urticae & A & NC 010526 & 13,103 & 84.27 & 0.026 & -0.016 & 10,226 & 84.00 & 646 & 85.91 & 991 & 85.27 & 44 & 95.45 & {$[18]$} \\
\hline U. foiliig & A & $\underline{N C 011036}$ & 14,738 & 72.95 & 0.201 & -0.279 & 10,679 & 71.83 & 649 & 74.35 & 1016 & 74.35 & $387-644$ & $76.49-77.33$ & unpub. \\
\hline V. destructor & $P$ & $\underline{N C} 004454$ & 16,477 & 80.02 & -0.021 & 0.177 & 10,728 & 79.22 & 726 & 80.44 & 1149 & 83.12 & 2174 & 79.71 & [25] \\
\hline W. hayashiig & A & NC 010595 & 14,857 & 72.97 & 0.264 & -0.305 & 10,573 & 73.01 & 625 & 75.05 & 1045 & 77.42 & 1403 & 68.28 & unpub. \\
\hline Li. polyphemus & i & NC 003057 & 14,985 & 67.60 & 0.111 & -0.399 & 11,077 & 66.43 & 799 & 69.70 & 1296 & 71.00 & 348 & 81.3 & {$[30,31]$} \\
\hline
\end{tabular}

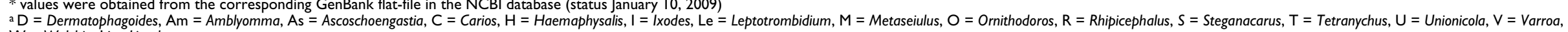

$\hat{W} \begin{aligned} & W=\text { Walchia, } \mathrm{Li}=\text { Limulus } \\ & \mathrm{b} \mathrm{S}=\text { Acari superorder }(\mathrm{A}=\text { Acariformes, } \mathrm{P}=\text { Parasitiformes })\end{aligned}$

CPCG = Protein coding genes

을 duplications of the control region were also considered

fGC and AT-skew for the strand cod

(46]

$\mathrm{h}$ L. pallidum has a duplication of 165 -rRNA; in this table the largest 165 -rRNA gene is considered

y i only single copy genes were considered for protein coding gene length calculation of $M$. occidentalis

iL. polyphemus belongs to the order of the Xiphosura within the class of the Merostomata 
$\operatorname{trnP} / \operatorname{trn} V(11 \mathrm{bp}), \operatorname{trn} V / \operatorname{trnK}(7 \mathrm{bp}), \operatorname{trn} W / \operatorname{trn} Y(1 \mathrm{bp})$, trnY/nad1 (4 bp), trnI/trnQ (1 bp) and $\operatorname{trn} L_{1} / \operatorname{trnC}(5 \mathrm{bp})$. No overlap was found between protein coding genes. Small non-coding regions (>20 bp) are present between $\operatorname{trnS}_{2} / \operatorname{trn} A$ (25 bp), trnA/trnP (20 bp) and nad1/nad6 (28 bp). A large non-coding region is positioned between $t r n F$ and $t_{n} S_{1}$ (286 bp). Twenty-five genes of the $\mathrm{mt}$ genome of $D$. pteronyssinus are transcribed on the majority strand (J-strand), whereas the others are oriented on the minority strand (N-strand).

The mt genome of the horseshoe crab Limulus polyphemus is considered to represent the ground pattern for arthropod $\mathrm{mt}$ genomes $[30,31]$. Comparing the $D$. pteronyssinus genome to this sequence revealed that only 11 of the 38 gene boundaries in L. polyphemus are conserved in D. pteronyssinus (Fig. 3 [32]). Moreover, by making use of the pattern search function in the Mitome-database ([33], status January 10, 2009), the mt gene order of D. pteronyssinus appeared to be unique among arthropods. Remarkably, the relative position of $\mathrm{trnL}_{2}$ (between nad1 and 16S-rRNA), which differentiates the Chelicerata, Myriapoda and Onychophora from the Insecta and Crustacea according to Boore $[12,34]$, is not conserved. However, Boore's hypothesis was based on mt genome data from only 2 Chelicerata that were available in 1998. At present, 41 complete chelicerate mt genomes are available in the NCBI-database ([19], status January 10, 2009). Out of these, only 29 depict the specific arrangement of $t r n L_{2}$ between nad1 and 16S-rRNA (see additional file 1 for an overview of gene arrangements of chelicerate $\mathrm{mt}$ genomes). This illustrates that care should be taken when general rules are deduced from limited datasets.

Mt gene arrangements have already provided strong support toward the resolution of several long-standing controversial phylogenetic relationships [12]. Surprisingly, the mt gene order of $D$. pteronyssinus differs considerably from that of other mites (see additional file 1). Comparing the $D$. pteronyssinus $\mathrm{mt}$ genome to the $\mathrm{mt}$ sequence of the oribatid S. magnus [22], the closest relative of D. pteronyssinus, revealed that only 6 of the 22 gene boundaries in S. magnus are conserved in D. pteronyssinus (Fig. 3).

Extending this analysis to the other Acari mt genomes showed that in several cases the set of neighboured genes that were not separated during the evolution [35] was greater between members of different superorders (e.g. D. pteronyssinus (Acariformes) and Rhipicephalus sanguineus (Parasitiformes)) than between members of the same superorder (e.g. D. pteronyssinus (Acariformes) and T. urticae (Acariformes)) (Table2). Exclusion of tRNAs in our analysis showed a similar trend, suggesting that protein coding genes were also involved in $\mathrm{mt}$ gene rearrangements. These results indicate that $\mathrm{mt}$ gene orders seem less useful for deduction of phylogenetic relationships between superorders within the Acari. However, comparing gene order might be more powerful to establish phylogenetic relations within families, as was previously proposed [14,36]. In the case of the Ixodidae family, it was shown that the division of Prostriata (Ixodes sp.) and Metastriata (R. sanguineus, Amblyomma triguttatum, Haemaphysalis flava) could be linked to mt gene arrangements $[37,38]$.

\section{Base composition and codon usage}

The overall AT-content of the mt genome of D. pteronyssinus is $72.6 \%$ (Table 1 ). This is within the range of the average AT-content of Acari mt genomes (74.6+/-4.0\%). The high AT-content is reflected in the codon usage (Table 3 [39]) with nucleotides ' $A$ ' and ' $T$ ' preferred over ' $C$ ' and ' $G$ ' on the wobble position and the predominant use of codons deficient in ' $\mathrm{C}$ ' or ' $\mathrm{G}$ '. For example, the most frequently used codons are TTT (F) (105 codons per 1000 codons) and TTA $\left(\mathrm{L}_{2}\right)$ (78 codons per 1000 codons).

Metazoan mt genomes usually present a clear strand bias in nucleotide composition [40]. This is probably due to asymmetric patterns of mutations during transcription and replication when one strand remains transiently in a single-stranded state, making it more vulnerable to DNA damage [41]. However, in the case of mtDNA-replication, this hypothesis is not without controversy [42-45]. The strand bias in nucleotide composition can be measured as GC- and AT-skews ((G\%-C\%)/(G\%+C\%) and (A\%-T\%)/ (A\%+T\%), respectively) [46]. The overall GC- and ATskews of the J-strand of the D. pteronyssinus mt genome are 0.194 and -0.199 , respectively. These are the most extreme values encountered within mite mt genomes up till now (Table 1) and they are reversed compared to the usual strand biases of metazoan mtDNA (negative GC-skew and positive AT-skew for the J-strand). Moreover, a positive GC-skew for mite mt genomes seems to be rare since at present, it was only encountered in Varroa destructor. Although hypothetical, it could be the result of a strand swap of the control region [40]. This region contains all initiation sites for transcription [47] and an inversion of the control region is expected to produce a global reversal of asymmetric mutational constraints in the mtDNA, resulting with time in a complete reversal of strand compositional bias [40]. The asymmetrical directional mutation pressure is also reflected in the codon usage of genes oriented in opposite directions [48]. Whereas NNG and NNU codons are preferred over NNA and NNC codons on the J-strand, genes on the N-strand show the exact opposite trend (see additional file 2 for an across-strand ( $\mathrm{N}$ and $\mathrm{J})$ comparison of frequencies of codons ending with the same nucleotide). 


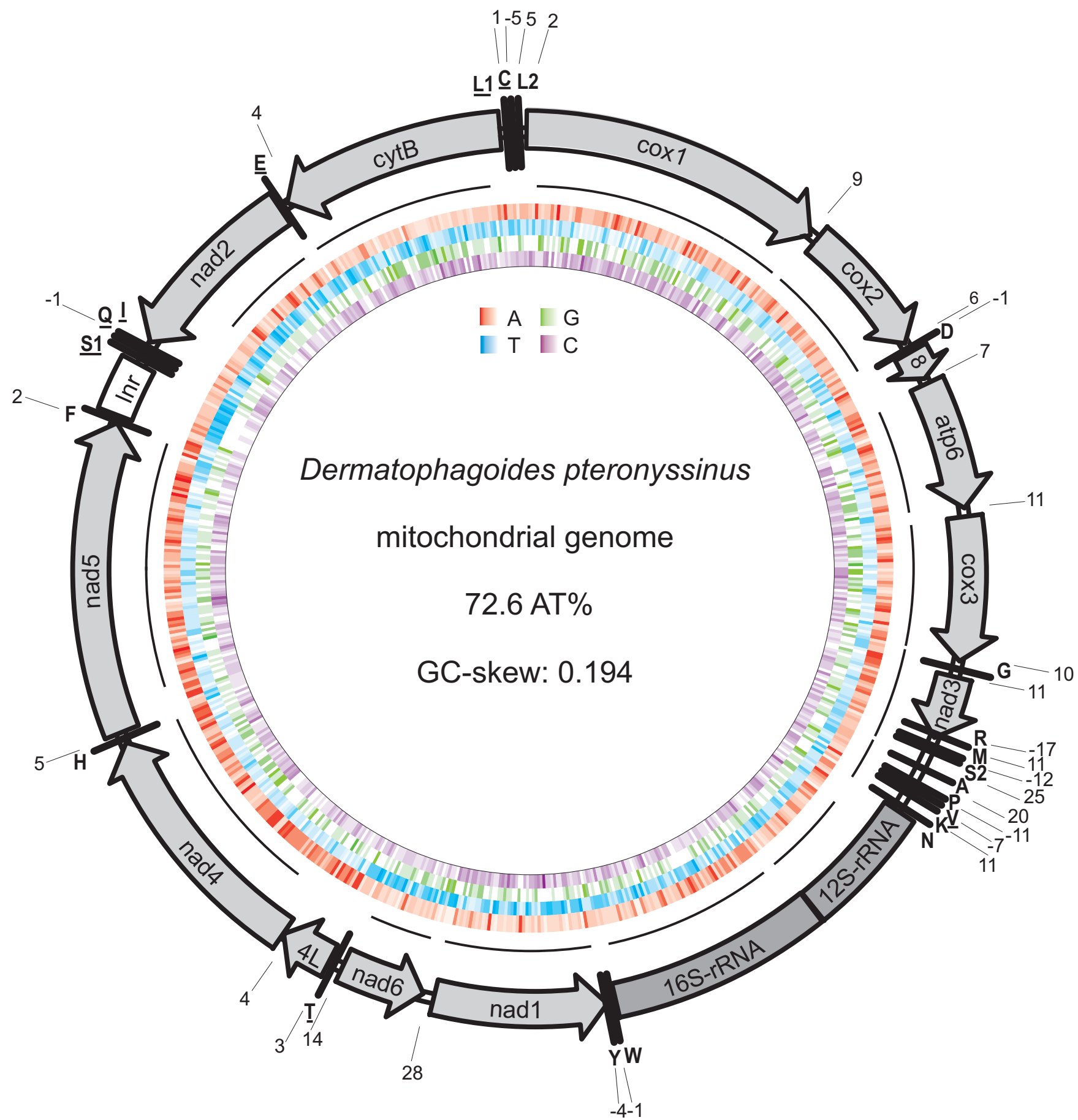

Figure I

Schematic representation of the $\mathbf{m t}$ genome of $\mathbf{D}$. pteronyssinus. Except for atp8 $(=8)$ and nad 4 (= $4 \mathrm{~L})$ protein coding and ribosomal genes are presented as outlined in the abbreviations section. tRNA genes are abbreviated using the one-letter amino acid code, with $L_{1}=C U N ; L_{2}=U U R ; S_{1}=A G N ; S_{2}=U C N$. RNAs on the N-strand are underlined. Numbers at gene junctions indicate the length of small non-coding regions where negative numbers indicate overlap between genes. A-,T-, G- and $\mathrm{C}$-content of the $\mathrm{mt}$ genome is represented using a red, blue, green and purple colour graded circle, respectively. Black curved lines on the outside of these circles represent $\mathrm{mt}$ genome coverage by Dermatophagoides ESTs (see additional file 5 for sequences of Dermatophagoides ESTs covering the $\mathrm{mt}$ genome of $D$. pteronyssinus). 


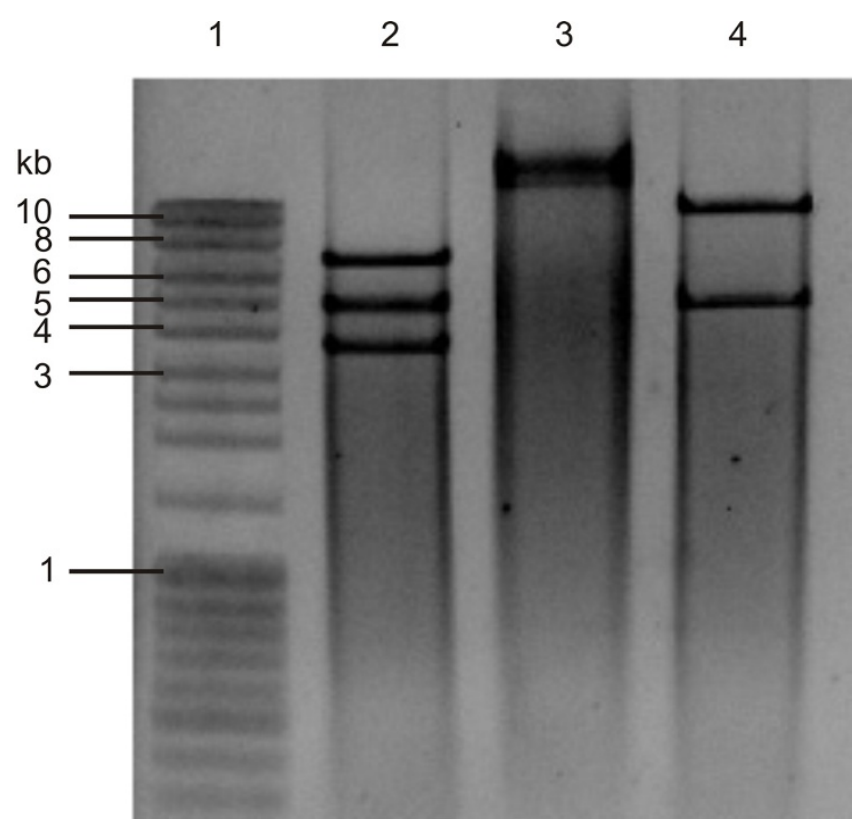

Figure 2

Restriction digest of rolling circle amplified mitochondrial DNA of $\boldsymbol{D}$. pteronyssinus. Rolling circle amplified mtDNA, undigested (lane 3) and digested with Xmnl (lane2) and EcoRI (lane 4). Molecular marker used was MassRuler DNA ladder Mix (Fermentas) (lane I).

\section{Protein coding genes}

Nine proteins are encoded by genes on the J-strand (cox1, cox2, cox3, atp6, atp8, nad3, nad4, nad4L, nad5), while four are encoded by genes on the N-strand (nad1, nad6, nad2, cytB). The total length $(10,826 \mathrm{bp})$ and AT-content $(71.61 \%)$ of the protein-coding genes are within the range of values typical for Acari $(10,639.0+/-272.0$ bp; $74.0+$ + - 4.0\%, respectively) (Table 1 ). Compared to other mite mt proteins, cox $1, \operatorname{cox} 2$ and $\mathrm{cytB}$ are best conserved. On the other hand, atp8, nad 6 and nad4L showed lowest similarity values (see additional file 3 for the average identity and similarity \% of mt proteins of D. pteronyssinus).

Start and stop codons were determined based on alignments with the corresponding genes and proteins of other mite species. In the case of stop codons, we could also benefit from available expressed sequence tags (ESTs) of D. pteronyssinus $(\mathrm{n}=1797)$ and D. farinae $(\mathrm{n}=1735)$ (Fig. 1) [49]. As for other metazoan mt proteins, unorthodox initiation codons are used [20] (see additional file 4 for start and stop codons of protein coding genes of Acari mt genomes). Eight genes (cox2, atp6, cox3, nad3, nad6, nad $4 L$, nad4, cytB) use the standard ATG start codon, 3 genes (cox1, nad1, nad2) start with ATA and nad5 initiates with ATT. atp8 most likely starts with codon TTG.
Eleven genes employ a complete translation termination codon, either TAG $(\operatorname{cox} 1, \operatorname{cox} 3)$ or TAA $(\cos 2$, atp 8, atp6, nad1, nad3, nad6, nad4L, nad5, cytB). With the exception of nad3, atp 8 and nad4L, D. pteronyssinus ESTs for all these genes confirmed the position of the stop codon (Fig. 1, see additional file 5 for sequences of Dermatophagoides ESTs covering the mt genome of D. pteronyssinus). Berthier et al. [50] showed that the adjacent genes, nad4L/nad4 and atp8/atp6, were transcribed and translated as a bicistronic mRNA in the model organism Drosophila melanogaster. However, as no ESTs were found that aligned with the nad4L/nad4 and atp8/atp6 gene boundaries, it could not be confirmed whether this was also the case for D. pteronyssinus. Despite its efficiency, the use of sequence alignments to determine the position of stop codons resulted in several cases in overlapping genes. For example, based on a highly conserved tryptophan at the C-terminal end of Acari nad3 proteins, a stop codon was positioned despite the resulting 17 bp overlap with trnaR. The two remaining genes (nad2 and nad4) are likely equipped with a truncated stop codon (T). Polyadenylation of the mRNA is needed in these cases to form a fully functional TAA stop codon [51]. Although speculative, ESTs of D. farinae confirm the truncated stop of nad4 (Fig. 1, see additional file 5).

\section{Transfer RNAs}

Fourteen tRNAs are encoded on the J-strand and 8 on the $\mathrm{N}$-strand (Fig. 1). Secondary structures were predicted for all tRNAs (Fig. 4). With the exception of $t r n S_{1}$ (UCU instead of GCU in L. pallidum) and trnP (UGG instead of AGG in S. magnus), all anticodon sequences were identical to those of L. pallidum and S. magnus, the only acariform mites for which tRNA secondary structures have been reported [22,24]. Usually, $\mathrm{T}$ is in the first anticodon position for tRNAs that recognise either four-fold degenerate codon families or NNR codons. G is usually in this position only to specifically recognize NNY-codons [52]. Except for $\operatorname{trn} M$, all of the D. pteronyssinus mt tRNAs follow this pattern. trnM has the anticodon CAT (to recognise both ATG and ATA), which is the case for almost all animal mt systems [52] (Fig. 4).

Only one tRNA lacks the D-arm: $\operatorname{trn} S_{1}$, as is common for most metazoans. With the exception of $\operatorname{trn} C, \operatorname{trn} V$ and $t_{n} S_{1}$, all tRNAs have T-arm variable loops (TV replacement loops) instead of the T-arm. Similar structures were found for tRNAs of L. pallidum [24] and S. magnus [22]. The absence of the T-arm is a typical feature for tRNAs of Chelicerata belonging to the orders of the Araneae, Scorpiones and Thelyphonida. However, other taxa within the Chelicerata (Amblypygi, Opiliones, Ricinulei, Solifugae and ticks) possess typical metazoan cloverleaf tRNAs [13]. Masta and Boore [13] suggested a multi-step evolutionary process in an attempt to understand how so many tRNAs 
Limulus polyphemus (Arthropod ground pattern)

(J)

(N)

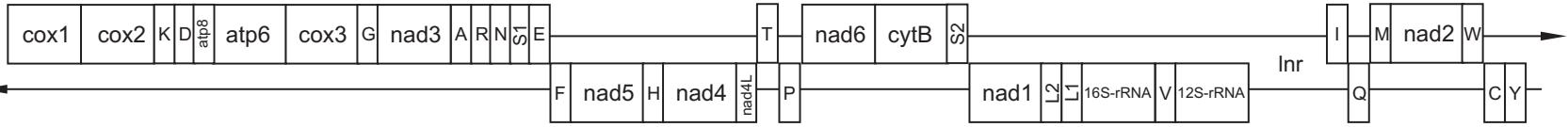

Dermatophagoides pteronyssinus

(J)

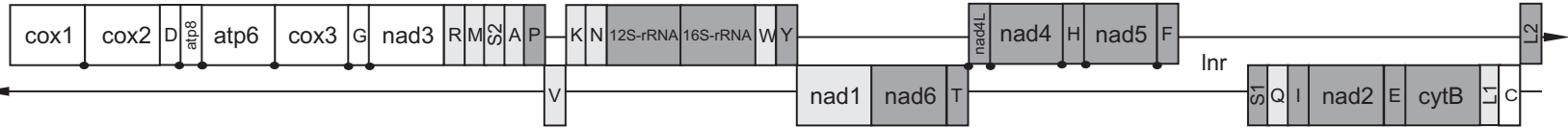

Steganacarus magnus

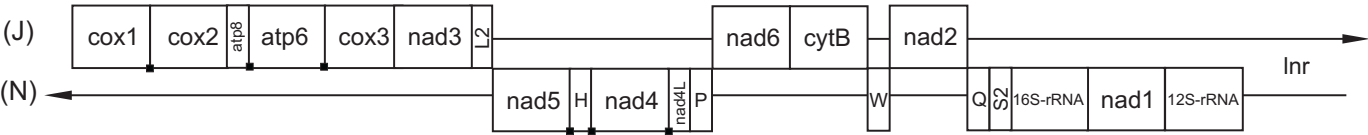

Figure 3

Mitochondrial gene arrangement of Limulus polyphemus, Dermatophagoides pteronyssinus and Steganacarus magnus. Graphical linearisation of $\mathrm{mt}$ genomes is presented according to [32]. Gene sizes are not drawn to scale. J stands for majority and $\mathrm{N}$ for minority strand. Protein coding and rRNA genes are abbreviated as in the abbreviations section. tRNA genes are abbreviated using the one-letter amino acid code, with $L_{1}=C U N ; L_{2}=U U R ; S_{1}=A G N ; S_{2}=U C N$. White boxes represent genes with the same relative position as in the arthropod ground pattern, $L$. polyphemus. Light-gray boxes represent genes that changed positions relative to $L$. polyphemus; dark-gray boxes represent genes that changed both position and orientation. Circular dots between the genes of $D$. pteronyssinus represent conserved gene boundaries compared to $L$. polyphemus. Square dots between the genes of $S$. magnus represent conserved gene boundaries compared to $D$. pteronyssinus.

in these chelicerate groups could lose their T-arm. According to this speculative theory, changes in mt ribosomes, resulting in the fact that the loss of arms from tRNAs was tolerated $[53,54]$, and/or changes in specific elongation factors [55-57] are considered as a first step in this process.

Table 2: Pairwise common interval distance matrix of $\mathrm{mt}$ gene orders of Acari*.

\begin{tabular}{|c|c|c|c|c|c|c|c|c|c|c|}
\hline & $D p$ & 1 & Rs & $V d$ & La & Tu & $A$ & Wh & Uf & Sm \\
\hline D. pteronyssinus $(D p)$ & $1326 / 204$ & 70 & 74 & 46 & 18 & 14 & 18 & 18 & 16 & - \\
\hline Ixodes sp. $(I)^{\text {a }}$ & 56 & $1326 / 204$ & 388 & 278 & 34 & 26 & 68 & 70 & 78 & - \\
\hline R. sanguineus $(R s) b$ & 86 & 78 & $1326 / 204$ & 202 & 36 & 26 & 72 & 70 & 74 & - \\
\hline V. destructor $(V d)$ & 56 & 204 & 78 & $1326 / 204$ & 36 & 18 & 60 & 60 & 54 & - \\
\hline L. akamushi $(L a)^{c}$ & 20 & 36 & 24 & 36 & $1326 / 204$ & 20 & 100 & 98 & 90 & - \\
\hline T. urticae $(T u)$ & 22 & 26 & 22 & 26 & 22 & $1326 / 204$ & 20 & 20 & 16 & - \\
\hline Ascoschoengastia sp.(A) & 34 & 38 & 46 & 38 & 44 & 28 & $1326 / 204$ & 278 & 130 & - \\
\hline W. hayashii (Wh) & 24 & 48 & 32 & 48 & 32 & 46 & 40 & $1326 / 204$ & 122 & - \\
\hline U. foilii (Uf) & 30 & 90 & 44 & 90 & 38 & 32 & 40 & 42 & $1326 / 204$ & - \\
\hline S. magnus $(\mathrm{Sm})^{d}$ & 60 & 132 & 72 & 132 & 28 & 22 & 34 & 62 & 80 & $-/ 204$ \\
\hline
\end{tabular}

*bold numbers represent pairwise common interval distances between $\mathrm{mt}$ gene orders of Acari (37 genes in total), while italic numbers represent pairwise common interval distances between $\mathrm{mt}$ gene orders of Acari without tRNAs ( 15 genes in total) (L. pallidum and M. occidentalis were excluded from the dataset as the genomes contain duplicated genes whereas other genes are absent). Accession numbers of Acari mt genomes are listed in Table I.

a similar gene order as L. polyphemus, Ornithodoros sp. and C. capensis

b similar gene order as $H$. flava and A. triguttatum

c similar gene order as $L$. deliense

d due to lack of tRNAs only protein coding gene and rRNA order comparison was possible 
Table 3: Relative synonymous codon usage (RSCU) and number of codons per 1000 codons (NCI000) in the protein coding genes of the mitochondrial genome of $D$. pteronyssinus.

\begin{tabular}{|c|c|c|c|c|c|c|c|c|c|c|c|c|c|c|c|}
\hline $\begin{array}{c}\text { Amino } \\
\text { acid }\end{array}$ & codon & RSCU* & $\mathrm{NCIO00}$ & $\begin{array}{l}\text { Amino } \\
\text { acid }\end{array}$ & codon & RSCU & $\mathrm{NCl} 000$ & $\begin{array}{c}\text { Amino } \\
\text { acid }\end{array}$ & codon & $\mathrm{RSCU}$ & $\mathrm{NCl} 000$ & $\begin{array}{c}\text { Amino } \\
\text { acid }\end{array}$ & codon & RSCU & $\mathrm{NCI} 000$ \\
\hline \multirow[t]{2}{*}{$\mathbf{F}$} & TTC & 0.24 & 14.14 & $\mathbf{S 2}$ & TCA & 1.13 & 15.52 & $\mathbf{Y}$ & TAC & 0.48 & 11.09 & C & TGC & 0.33 & 2.77 \\
\hline & TTT & 1.76 & 105.60 & & TCC & 0.43 & 5.82 & & TAT & 1.52 & 35.20 & & TGT & 1.67 & 14.14 \\
\hline \multirow[t]{2}{*}{ L2 } & TTA & 3.43 & 78.7I & & TCG & 0.14 & 1.94 & & & & & $\mathbf{W}$ & TGA & 1.11 & 12.75 \\
\hline & TTG & 0.81 & 18.57 & & TCT & 3.81 & 52.11 & & & & & & TGG & 0.89 & 10.25 \\
\hline \multirow[t]{4}{*}{ LI } & CTA & 0.74 & 16.91 & $\mathbf{P}$ & $\mathrm{CCA}$ & 1.53 & $|4.4|$ & $\mathbf{H}$ & CAC & 0.50 & 4.16 & $\mathbf{R}$ & CGA & 1.37 & 3.88 \\
\hline & СТС & 0.10 & 2.22 & & $\mathrm{CCC}$ & 0.35 & 3.33 & & CAT & 1.50 & 12.47 & & CGC & 0.00 & 0.00 \\
\hline & CTG & 0.10 & 2.22 & & CCG & 0.24 & 2.22 & $\mathbf{Q}$ & CAA & 1.68 & 8.59 & & CGG & 0.49 & 1.39 \\
\hline & CTT & 0.83 & 19.12 & & CCT & 1.88 & 17.74 & & CAG & 0.32 & 1.66 & & CGT & 2.15 & 6.10 \\
\hline \multirow[t]{2}{*}{$\mathbf{I}$} & ATC & 0.40 & 16.08 & $\mathbf{T}$ & $A C A$ & 1.33 & 13.58 & $\mathbf{N}$ & AAC & 0.63 & 10.53 & SI & AGA & 0.99 & 13.58 \\
\hline & ATT & 1.60 & 64.30 & & $A C C$ & 0.44 & 4.43 & & AAT & 1.37 & 23.00 & & AGC & 0.16 & 2.22 \\
\hline \multirow[t]{2}{*}{$\mathbf{M}$} & ATA & 1.58 & 57.65 & & ACG & 0.05 & 0.55 & $\mathbf{K}$ & AAA & 1.67 & 28.55 & & AGG & 0.61 & 8.31 \\
\hline & ATG & 0.42 & 15.52 & & ACT & 2.18 & 22.17 & & AAG & 0.33 & 5.54 & & AGT & 0.73 & 9.98 \\
\hline \multirow[t]{4}{*}{$\mathbf{v}$} & GTA & 1.09 & 21.06 & A & GCA & 0.71 & 4.99 & D & GAC & 0.69 & 6.93 & $\mathbf{G}$ & GGA & 0.96 & 13.86 \\
\hline & GTC & 0.17 & 3.33 & & GCC & 0.59 & 4.16 & & GAT & 1.31 & 13.03 & & GGC & 0.15 & 2.22 \\
\hline & GTG & 0.43 & 8.31 & & GCG & 0.16 & 1.11 & $\mathbf{E}$ & GAA & 0.95 & 10.81 & & GGG & 1.45 & 21.06 \\
\hline & GTT & 2.31 & 44.62 & & GCT & 2.53 & 17.74 & & GAG & 1.05 & 11.92 & & GGT & 1.44 & 20.79 \\
\hline
\end{tabular}

* RSCU is the number of times a particular codon is observed relative to the number of times a codon would be observed in the absence of any codon usage bias [39]. 

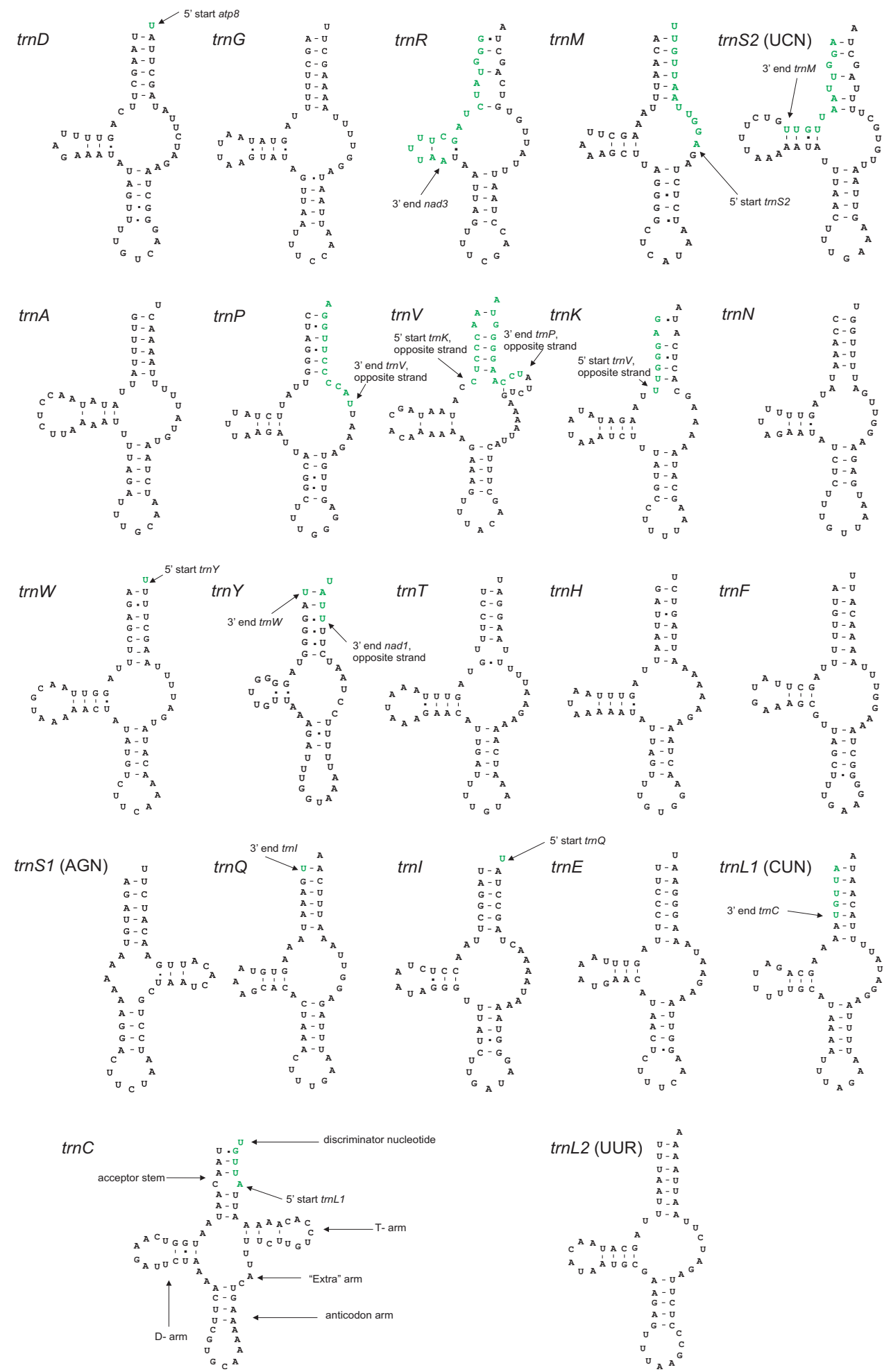

\section{Figure 4}

Inferred secondary structures of the $\mathbf{2 2}$ mitochondrial tRNAs from $\mathbf{D}$. pteronyssinus. tRNAs are shown in the order of occurrence in the $\mathrm{mt}$ genome starting from coxl. Locations of adjacent gene boundaries are indicated with arrows. Green font indicates that the sequence is part of the adjacent gene. Inferred Watson-Crick bonds are illustrated by lines, whereas GU bonds are illustrated by dots. 
Only 7 of the 22 tRNAs have a completely matched $7 \mathrm{bp}$ acceptor stem (trnG, trnW, trnH, trnF, $\operatorname{trn} E, \operatorname{trn} L_{1}$ and $\operatorname{trn} L_{2}$ ). A maximum of 3 mismatches in this stem is found in trnR. In contrast, almost all tRNAs (18) possess a completely matched $5 \mathrm{bp}$ anticodon stem. $\operatorname{trn} \mathrm{C}$, $\operatorname{trnS}_{1}$ and $\operatorname{trnN}$ have a single mismatch whereas $\operatorname{trn} Y$ has two mismatches in this stem. All tRNAs, except $\operatorname{trn} L_{2}$, have a symmetric anticodon loop consisting of 2 bp up- and 2 bp downstream of the $3 \mathrm{bp}$ anticodon. The anticodon loop of $\mathrm{trnL}_{2}$ consists of 2 nucleotides preceding the anticodon and 3 nucleotides immediately following it. This kind of aberrant anticodon loops have also been reported for the twohumped camel Camelus bactrianus ferus $\left(\operatorname{trnS}_{2}\right)$ [58] and the scorpion Mesobuthus gibbosus ( $\operatorname{trnH}$ and $\operatorname{trn} N$ ) [59]. As mentioned before, sequences of some tRNAs overlap with neighbouring genes. The extreme examples are $t r n R, t r n S_{2}$ and $t r n V$. trnR overlaps with the adjacent gene nad 3 on the same strand for $17 \mathrm{bp}$ at its 3 '-end whereas $t r n S_{2}$ overlaps with the adjacent gene trnM on the same strand for $12 \mathrm{bp}$ at its 3 '-end. $\operatorname{trn} V$ overlaps with the adjacent gene $\operatorname{trn} P$ on the opposite strand for $11 \mathrm{bp}$ at its $3^{\prime}$-end and with trnK on the opposite strand for $7 \mathrm{bp}$ at its 5 '-start. Despite these overlaps, we consider these genes not likely to be pseudogenes. First of all, their sequence is relatively well conserved when compared to corresponding genes of other Acari. Secondly, besides sequence conservation they depict a conserved secondary structure. Thirdly, an EST [GenBank: CB284825] of the related species D. farinae was found corresponding to the region covering $\operatorname{trnR}$, $t r n M$ and $t r n S_{2}$ of D. pteronyssinus indicating that the genes are expressed (see additional file 6 for an alignment of $\operatorname{trn} R, \operatorname{trnM}$ and $t r n S_{2}$ of $D$. pteronyssinus with an EST of $D$. farinae). Finally, and most importantly, stem mismatches and sequence overlap are not uncommon for mt tRNAs of arachnids $[13,60]$, and are probably repaired by a posttranscriptional editing process $[54,61]$.

\section{Non-coding regions}

The largest non-coding region ( $286 \mathrm{bp}$ ) is flanked by $\operatorname{trnF}$ and $t r n S_{1}$. It is highly enriched in AT $(91.61 \%)$ and can form stable stem-loop secondary structures. Based on these features, it possibly functions as a control region $[20,62]$. With the exception of T. urticae $(95.45 \%)$, it has the highest AT-content of all Acari mt control regions (Table 1). The position of the non-coding region differs from most insect and arachnid mt genomes, where the region is mostly located in close proximity to $12 S$-rRNA ([62], see additional file 1 ).

Based on the sequence pattern, the control region can be subdivided in a repeat region and a stem-loop region. The first region (11,491-11,528 bp) contains several ATrepeats. In order to verify the exact number of repeats we resequenced this region. For this purpose, two flanking primers, Dp-Ms-F and Dp-Ms-R, were synthesised span- ning approximately $700 \mathrm{bp}$. The PCR product was cloned and ten independent clones were sequenced. This revealed that the number of AT-repeats varied between 7 to 28 , suggesting that this domain can be considered as a microsatellite [63]. This is remarkable as a mt microsatellite was never reported before for species belonging to the Chelicerata. Also in metazoan mtDNA such microsatellites are rare and have, to our knowledge, only been reported for butterflies [64], a dragonfish, Scleropages formosus [65], a bat, Myotis bechsteinii [66], a turtle, Pelomedusa subrufa [67] and several seal species [68-70].

The second region $(11,529-11,768 \mathrm{bp})$ holds two short palindromic sequences, TACAT and ATGTA, which are conserved in mt genomes of mammals [71] and fishes $[65,72]$. They can form a stable stem-loop structure (Fig. 5-A2), which might be involved as a recognition site for the arrest of J-strand synthesis [71]. Near this region other stem-loop structures could be folded (Fig. 5-A) but none of them had flanking sequences similar to those that are conserved in the control region of the mt genome of insects [62] and metastriate ticks [37].

As described before, four other stretches of non-coding nucleotides were found outside the control region. These short sequences can fold into stable stem-loop structures (Fig. 5-B, C, D) which may function as splicing recognition sites during processing of the transcripts [73].

\section{Ribosomal RNAs}

12S-rRNA and 16S-rRNA are located on the J-strand. This does not coincide with their position in most Chelicerata where they are located on the $\mathrm{N}$-strand (see additional file $1)$. The AT-contents of both genes are comparable $(72.9 \%$ and $76.1 \%$ for the $12 S$ - and $16 S-R N A$, respectively) and are within the range of rRNAs of other Acari $(76.5+/$ $4.2 \% ; 78.0+/-4.1 \%$, respectively). The sizes of the rRNAs (665 bp and $1078 \mathrm{bp}$ ) are slightly larger than those of other acariform mite rRNAs $(626.0+/-29.9$ bp and $1018.5+/-21.3 \mathrm{bp})$ but are shorter than those found in the Parasitiformes (706.0 +/- 17.5 bp and $1207.3+/-31.4$ bp) (Table 1).

The 12S-rRNA and 16S-rRNA genes of Leptotrombidium species (Acariformes: Trombidiformes: Trombiculidae) are $23.4 \%$ and $23.5 \%$ shorter than their counterparts in Drosophila yakuba. This substantial reduction is mainly caused by the loss of stem-loop structures at the 5 '-end of the rRNA genes [74]. To identify whether similar domains are absent in the rRNAs of D. pteronyssinus, we constructed their secondary structures (Fig. $6[75,76]$ ). This revealed that the D. pteronyssinus $12 S-r R N A$ indeed lacks similar stem-loops as L. pallidum, compared to D. yakuba. The structure also revealed 1 additional stem-loop (stem-loop 1) not present in $12 S-r R N A$ of $L$. pallidum. Like in $L$. palli- 


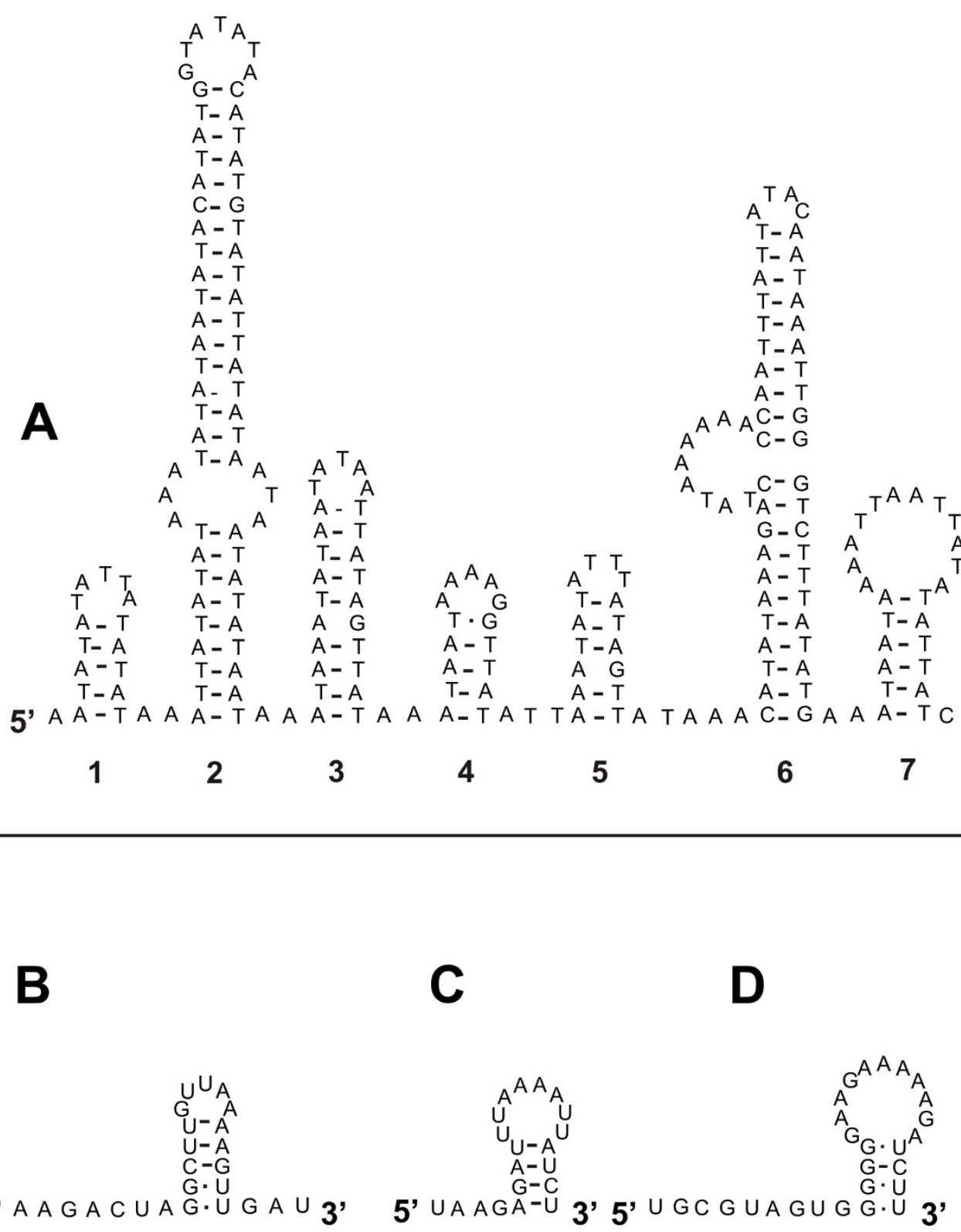

\section{Figure 5}

Secondary structures of non-coding regions of the $\mathbf{m t}$ genome of $\mathbf{D}$. pteronyssinus. Secondary structure of non-coding regions between $(\mathrm{A}) \operatorname{trnF}$ and $\operatorname{trn} \mathrm{S}_{1}$ (large non-coding region); (B) trnS $\mathrm{S}_{2}$ and $\operatorname{trn} A ;(\mathrm{C}) \operatorname{trn} A$ and $\operatorname{trnP}$; (D) nad I and nad6. All structures were constructed using Mfold [103]. Inferred Watson-Crick bonds are illustrated by lines, whereas GU bonds are illustrated by dots.

dum, one stem-loop replaces three stem-loops $(24,25$ and 26) whereas another replaces a region of four stem-loops $(39,40,41$ and 42) of the D. yakuba 12S-rRNA [74]. Based on the modelled structure in combination with an alignment of other acariform 12S-rRNAs, the greatest sequence conservation was found in the loop region of stem-loops 21 and 27 and the region between stem-loops 48 and 50.
In analogy to the $16 S-r R N A$ gene of $L$. pallidum, the main deletions of the D. pteronyssinus 16S-rRNA are located at the 5 '-end. With the exception of D19, all stem-loops of $L$. pallidum are present in $D$. pteronyssinus. We also discovered three additional stem-loops (C1, E2 and E19) which are absent in the 16S-rRNA of L. pallidum. The 3'-end of the $16 S-r R N A$ structure is best conserved compared to other acariform 16S-rRNAs. This is in agreement with the idea that this region is the main component of the peptidyl- 


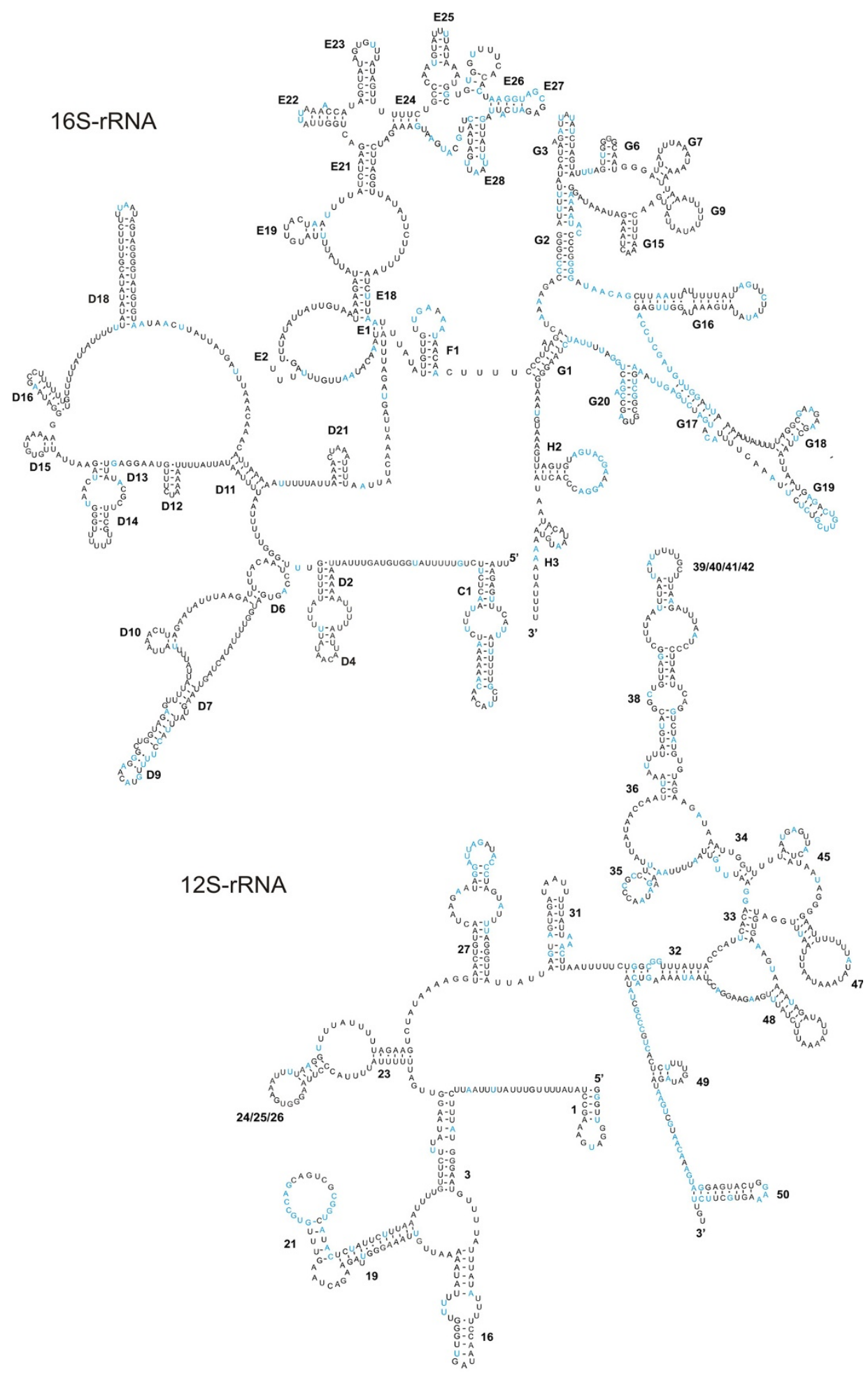

\section{Figure 6}

I 6S-rRNA and I 2S-rRNA secondary structures of the mitochondrial genome of $D$. pteronyssinus. The numbering of the stem-loops is after de Rijk et al. [75] for I6S-rRNA and after van de Peer et al. [76] for I2S-rRNA. Blue coloured nucleotides show $100 \%$ identity when aligned to I 2S-rRNA and I6S-rRNA genes from other Acariformes (as listed in Table I). Inferred Watson-Crick bonds are illustrated by lines, whereas GU bonds are illustrated by dots. 
transferase centre, and as such most vulnerable to mutations [73]. Recently, the 12S-rRNA and 16S-rRNA secondary structures of $S$. magnus have been published [22]. The $12 S$-rRNA structure of $S$. magnus has 5 extra stem-loops $(2$, $4,5,40$ and 42) compared to the one of D. pteronyssinus whereas the 16S-rRNA lacks 6 stem-loops (D4, D16, E1, E2, E19 and G9) and has 5 stem-loops (cd1, D1, D17, D19, G13) not present in the 16S-rRNA of D. pteronyssinus.

It is still an open question how relatively well-conserved structures such as rRNAs can dramatically decrease in size while remaining functional. Wolstenholme et al. [53] and Masta [54] suggested a correlation between the occurrence of truncated rRNAs (compared to Drosophila) and the loss of the T-arm in tRNAs. The coincidence of short rRNAs and missing T-arms in tRNAs was also observed in $S$. magnus, L. pallidum and D. pteronyssinus. Other acariform mites like T. urticae, Ascoschoengastia sp. and Walchia hayashii also exhibit short rRNAs (Table 1) and the prediction of their tRNA secondary structures could further support this hypothesis. However, examples contradicting this hypothesis also occur e.g. pulmonate gastropods with tRNAs lacking T-arms have no truncated rRNAs. Therefore, it remains possible that truncation of both tRNAs and rRNA genes only reflects an independent trend towards minimisation of the mt genome as suggested by Yamazaki et al. [77].

\section{Phylogenetic analysis}

A phylogenetic tree was constructed based on nucleotide and amino acid sequences from all $\mathrm{mt}$ protein coding genes of Acari. The ILD-test [78] indicated a significant incongruence $(P=0.01)$ among data set partitions for nucleotide alignments and low congruence $(P=0.07)$ among data set partitions for amino acid alignments. A considerable debate exists on the utility of this test [7984]. However, the principle of Kluge [85] implies that all data should always be included in a combined analysis for any phylogenetic problem and therefore we combined data partitions for both amino acid and nucleotide alignments for phylogenetic analysis. A maximum parsimony (MP) analysis based on nucleotide alignments (data not shown) grouped $V$. destructor (Parasitiformes) within the Acariformes, close to D. pteronyssinus. This is in contrast with the generally accepted view on the phylogeny of the Acariformes and Parasitiformes [2,3]. As mentioned before, $V$. destructor and $D$. pteronyssinus both have a reversal of asymmetrical mutation pattern. When such reversals occurred independently, D. pteronyssinus and $V$. destructor could have acquired a similar base composition and as a consequence group together due to the longbranch attraction (LBA) phenomenon [40,86]. Modelbased methods such as maximum likelihood (ML) and Bayesian inference (BI) are less sensitive to LBA $[40,87]$ and were for this reason considered for phylogenetic analysis.

ML and BI analysis performed on the amino acid data set resolved trees with an identical topology (Fig. 7-A) in which $D$. pteronyssinus clusters with $S$. magnus, forming a sistergroup of the Trombidiformes. This is in agreement with the most recent views on the classification of the Acariformes [2-4]. The nucleotide data set resulted in similar trees, confirming the evolutionary position of $D$. pteronyssinus (Fig. 7-B). The only major inconsistency over the trees was the position of T. urticae. Although this species is generally considered as a member of the Trombidiformes [2-4], it was clustered with the sarcoptiform mites D. pteronyssinus and $S$. magnus in the trees based on the nucleotide dataset. (Fig. 7-B). However, the position in the different trees is questionable as it is supported by low bootstrap values/Bayesian posterior probabilities (Fig. 7$\mathrm{A} / \mathrm{B}$ ). Adding additional $\mathrm{mt}$ genome data from closely related taxa of T. urticae and from taxa located between $T$. urticae and Trombiculidae would probably position $T$. urticae with higher support values within the Trombidiformes.

In the trees based on the nucleotide dataset, $H$. flava is, compared to A. triguttatum, evolutionary closer related to $R$. sanguineus while in the trees based on the amino acid dataset this is the opposite. However, as the clustering of $H$. flava and $R$. sanguineus is in agreement with the most recent views on the classification of the Ixodida $[88,89]$, we consider the nucleotide topology as the most correct one. Murrell et al. [90] considers the Parasitiformes to be paraphyletic with respect to the Opilioacariformes, but as there are no complete mt genomes of Opilioacariformes available, we were not able to verify this hypothesis.

\section{Conclusion}

This is the first description of a complete mt genome of a species belonging to the Astigmata, a cohort within the Sarcoptiformes. Although the length, gene and AT-content are similar to other Acari mtDNA, the mt genome of D. pteronyssinus exhibits some interesting features. The gene order of D. pteronyssinus is completely different from that of other Acari mt genomes. Gene order comparison indicated that mt gene orders seem less useful for deduction of phylogenetic relationships between superorders within the Acari. GC- and AT-skews of the J-strand were very large and reversed as compared to those found in most metazoan mtDNA.

Compared to parasitiform mites, both D. pteronyssinus rRNAs were considerably shorter and almost all transfer RNAs lacked the T-arm. It would be interesting to investigate whether the occurrence of truncated rRNAs and the loss of the T-arm in tRNAs are correlated or just a trend 


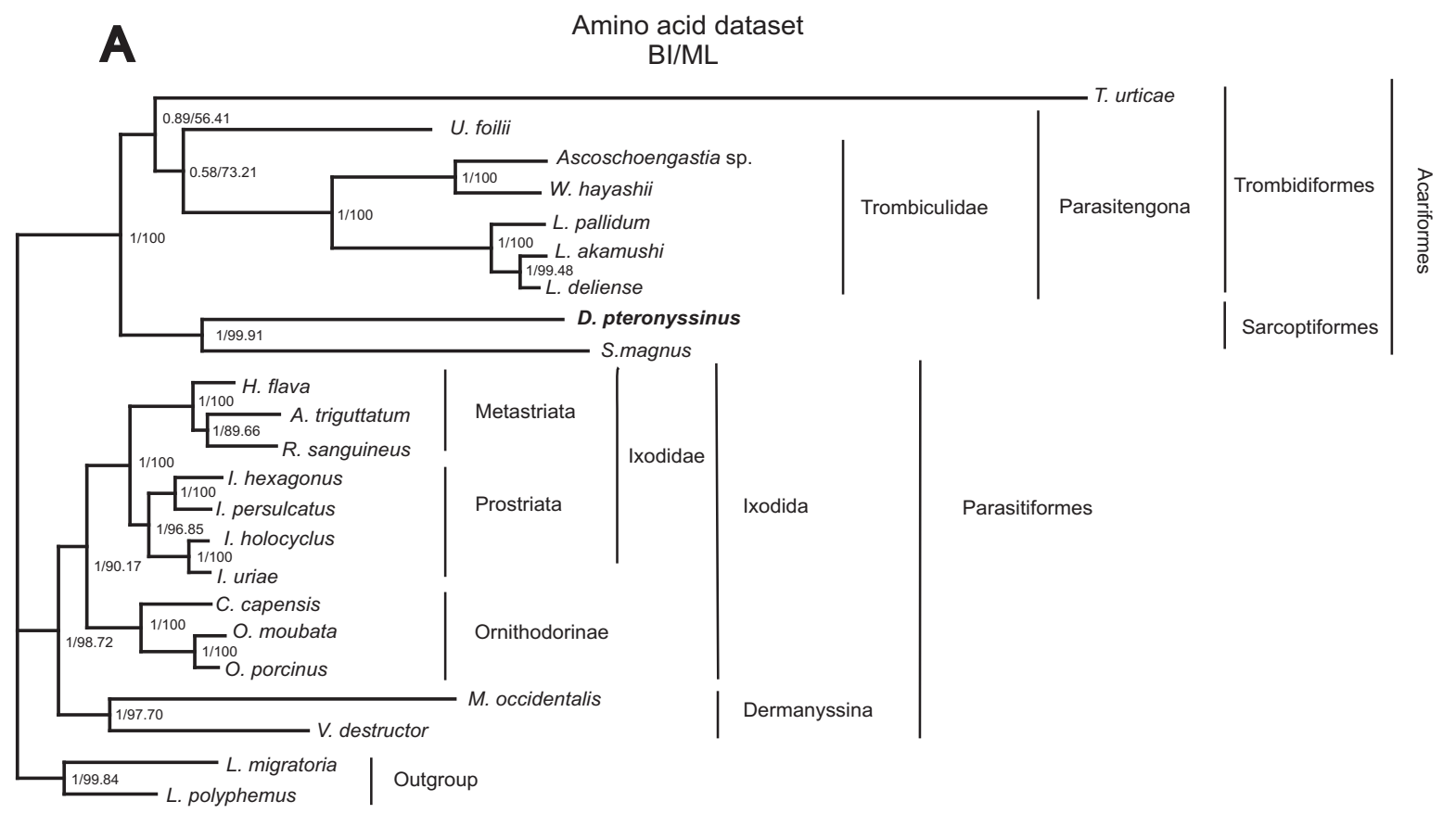

$\underline{0.1}$

B Nucleotide dataset $\mathrm{BI} / \mathrm{ML}$

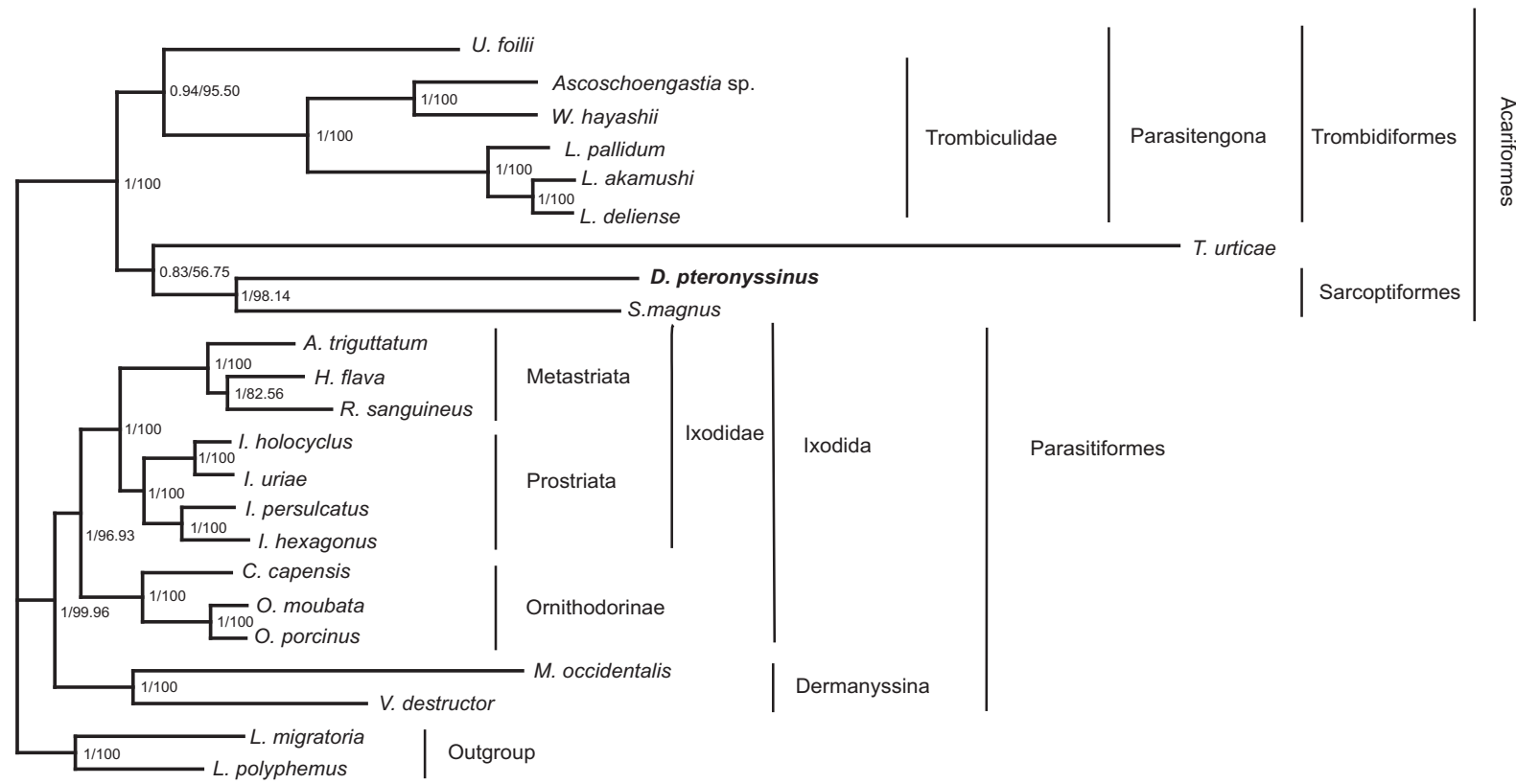

0.1

Figure 7

Phylogenetic trees of Acari relationships. Trees were inferred from amino acid (A) and nucleotide (B) datasets. All protein coding gene sequences were aligned and concatenated; ambiguously aligned regions were omitted by Gblocks $0.9 \mathrm{lb}$ [105]. Trees were rooted with two outgroup taxa (L. polyphemus and L. migratoria). Numbers behind the branching points are percentages from Bayesian posterior probabilities (left) and ML bootstrapping (right). Accession numbers for the different Acari $\mathrm{mt}$ genomes are listed in Table I. 
toward minimisation of the mt genome. Finally, phylogenetic analysis using concatenated $\mathrm{mt}$ gene sequences succeeded in recovering Acari relationships concordant with traditional views of phylogeny of Acari.

\section{Methods \\ Mite identification}

Upon arrival in the laboratory, mites were identified as $D$. pteronyssinus by J. Witters (ILVO, Belgium) and F. Th. M. Spieksma (Laboratory of Aerobiology, LUMC, The Netherlands) using morphological characteristics. To back up this identification, molecular techniques were applied. For this purpose DNA was extracted and used as a template for PCR. Primers 12SID-F and 12SID-R (see additional file 7 for primer sequences) successfully amplified a 316 bp fragment. BLASTn searches against non-redundant nucleotide sequences using the amplified fragment as query resulted in a perfect match with a mt $12 S-r R N A$ sequence of D. pteronyssinus [GenBank: AF529911].

\section{Mite strain, mass rearing and isolation}

The initial D. pteronyssinus culture was provided by D. Bylemans (Janssen Pharmaceutica, Belgium). Mites were cultured on a 1:1 mixture of Premium Gold (Vitacraft, Germany) and beard shavings at $75 \%$ R.H., $25^{\circ} \mathrm{C}$ and permanent dark conditions [91,92]. Mites were isolated from the colony using a modified heat-escape technique $[93,94]$. Briefly, mite cultures were transferred to small plastic petri dishes (75 $\mathrm{mm}$ in diameter, $28 \mathrm{~mm}$ high) with a lid on top. These dishes were placed in the dark on a hot plate set at $45^{\circ} \mathrm{C}$ (Bekso, Belgium). After 15-20 minutes the mites moved away from the heat source, formed groups on the lid of the petri dish and could be collected using a fine hair brush.

\section{DNA extraction}

Approximately $1000 \mathrm{D}$. pteronyssinus mites were collected in an Eppendorf tube and were ground in $800 \mu \mathrm{l}$ SDS-lysis buffer ( $400 \mathrm{mM} \mathrm{NaCl}, 200 \mathrm{mM}$ TRIS, $10 \mathrm{mM}$ EDTA, $2 \%$ SDS) using a small sterile plastic pestle (Eppendorf, Germany). After incubation for $30 \mathrm{~min}$ at $60^{\circ} \mathrm{C}$ under continuous rotation, a standard phenol-chloroform extraction was performed [95]. Total genomic DNA was precipitated with 0.7 volumes of isopropanol at $4{ }^{\circ} \mathrm{C}$ for 1 hour, centrifuged for 45 minutes at $21,000 \times \mathrm{g}$ and washed with $70 \%$ ethanol. Precipitated DNA was resolved in $50 \mu \mathrm{l} 0.1$ M Tris pH 8.2.

\section{PCR}

Standard PCR (amplicon < $500 \mathrm{bp}$ ) was performed in 50 $\mu \mathrm{l}$ volumes (38.5 $\mu \mathrm{l}$ double-distilled water; $5 \mu \mathrm{l}$ buffer; 2 $\mathrm{mM} \mathrm{MgCl}{ }_{2} ; 0.2 \mathrm{mM}$ dNTP-mix; $0.2 \mu \mathrm{M}$ of each primer; 1 $\mu \mathrm{l}$ template DNA and $0.5 \mu \mathrm{l} \mathrm{Taq}$ polymerase (Invitrogen, Belgium). PCR conditions were as follows: $2^{\prime} 94^{\circ} \mathrm{C}, 35 \times$ $\left(20^{\prime \prime} 92^{\circ} \mathrm{C}, 30^{\prime \prime} 53^{\circ} \mathrm{C}, 1^{\prime} 72^{\circ} \mathrm{C}\right)$ and $2^{\prime} 72^{\circ} \mathrm{C}$. The anneal- ing time was extended to 1 minute and the primer concentration was increased to $2 \mu \mathrm{M}$ when degenerate primers were used. Long PCR (amplicon > $500 \mathrm{bp}$ ) was performed with the Expand Long Range Kit (Roche, Switzerland) in $50 \mu \mathrm{l}$ volumes $(28.5 \mu \mathrm{l}$ double-distilled water; $10 \mu \mathrm{l}$ buffer; $0.5 \mathrm{mM}$ dNTP-mix; $0.3 \mu \mathrm{M}$ of each primer; $4 \mu \mathrm{l}$ $100 \%$ DMSO; $1 \mu \mathrm{l}$ template DNA and $1 \mu \mathrm{l}$ enzyme-mix). PCR conditions were: $2^{\prime} 94^{\circ} \mathrm{C}, 10 \times\left(10^{\prime \prime} 92^{\circ} \mathrm{C}, 20^{\prime \prime}\right.$ at a temperature that varies depending on the primers, $1 / \mathrm{kb}$ $\left.58^{\circ} \mathrm{C}\right), 25 \times\left(10^{\prime \prime} 92^{\circ} \mathrm{C}, 20^{\prime \prime}\right.$ at a temperature that varies depending on the primers, $1^{\prime} / \mathrm{kb} 58^{\circ} \mathrm{C}$ with $20^{\prime \prime}$ added for every consecutive cycle) and $7{ }^{\prime} 58^{\circ} \mathrm{C}$. All PCR products were separated by electrophoresis on a $1 \%$ agarose gel and visualised by EtBr staining. Fragments (amplicon < 1000 bp) of interest were excised from gel, purified with the QIAquick PCR Purification Kit (Qiagen, Belgium) and cloned into the pGEM-T vector (Promega, Belgium). After heat-shock transformation of E. coli (DH5 $\alpha$ ) cells, plasmid DNA was obtained by miniprep and inserted fragments were sequenced with SP6 and T7-primers. Long PCR products were sequenced by primer-walking. All sequencing reactions were performed by AGOWA sequencing service.

\section{Amplification of the mt genome}

Primers COXI-F and 12S-R, based on partial D. pteronyssinus cox1 and 12S-rRNA sequences [GenBank: $\underline{\text { YY525570 }}$ and AF529911, respectively] (see additional file 7 for primer sequences), successfully amplified a $4.6 \mathrm{~kb}$ sequence of the $\mathrm{mt}$ genome of $D$. pteronyssinus. Degenerate primers CYTB-F-Deg and CYTB-R-Deg (see additional file 7 for primer sequences), designed on conserved regions of Acari $c y t B$, amplified a partial $c y t B$ sequence from $D$. pteronyssinus. A specific primer COXI-R, designed from the 3' end of the $4.5 \mathrm{~kb}$ sequence in combination with the primer CYTB-F, designed from the partial $c y t B$ sequence, successfully amplified a $2.2 \mathrm{~kb}$ sequence. Another primer CYTB-R, designed from the 5 '-end of this $2.2 \mathrm{~kb}$ sequence, in combination with the primer $12 \mathrm{~S}$-F successfully amplified a $8.6 \mathrm{~kb}$ sequence, making the $\mathrm{mt}$ genome sequence complete.

\section{Annotation and bioinformatics analysis}

The complete genomic sequence was assembled and annotated using VectorNTI (Invitrogen, Belgium) according to Masta and Boore [60]. Open reading frames (ORFs) were identified with the program Getorf from the EMBOSS-package [96]. The obtained ORFs were used as query in BLASTp [97] searches against the non-redundant protein database at NCBI. Two large non-protein-coding regions were candidates for the rRNAs (16S and $12 \mathrm{~S}$ respectively). The boundaries were identified based on alignments and secondary structures of rRNA genes of other mite species. Sixteen of the 22 tRNAs were identified by tRNA-scan SE [98] with a cove cutoff score of 0.1 and 
the tRNA-model set to "nematode mito". The remaining tRNAs (trnM, trnV, trnY, trnS $S_{1}, \operatorname{trnI}, \operatorname{trnC}$ ) were determined in the unannotated regions by sequence similarity to tRNAs of other mite species. In order to obtain additional information on $\mathrm{mt}$ gene boundaries, BLASTn [97] searches of $D$. pteronyssinus tRNA, rRNA and protein encoding nucleotide sequences were carried out against ESTs [49] restricted to Dermatophagoides sequences ( $\mathrm{n}=$ 3532). ESTs with statistically significant matches (E-value cutoff: 0.1) were collected, checked for vector contamination and aligned by Clustal W [99] as implemented in BioEdit 7.0.1 [100] against the appropriate nucleotide sequence of D. pteronyssinus. MatGAT 2.02 was used to calculate similarity and identity values [101] of mt proteins. The identification of gene subsets that appear consecutively in different genomes was performed by common interval distance analysis using CREx [102] (see additional file 8 for input data of the CREx program).

\section{Construction of secondary structures of RNAs and non- coding regions}

Secondary structures of tRNAs were determined following the method of Masta and Boore [60]. Secondary structures of tRNAs were drawn with CorelDraw 12.0 (Corel Corporation, Canada). The rRNA genes of $D$. pteronyssinus were aligned with those of other Acariformes and conserved areas were identified. These regions were mapped on the published structures of L. pallidum rRNA [74]. Regions lacking significant homology were folded using Mfold [103]. Secondary structures of rRNAs were drawn using the RnaViz2 program [104] and afterwards modified with CorelDraw 12.0 (Corel Corporation, Canada). Secondary structures of non-coding regions were folded using Mfold [103]. When multiple secondary structures were possible, the most stable (lowest free energy $(-\Delta G)$ ) one was preferred. Drawing and editing of these structures was done in a similar way as for rRNA secondary structures.

\section{Rolling circle amplification and restriction enzyme digestion}

Extraction and rolling circle amplification of the mtDNA of D. pteronyssinus was done according to Van Leeuwen $e t$ al. [18]. Rolling circle amplified mtDNA was digested with two enzymes (XmnI and EcoRI; New England Biolabs) following the manufacturer's instructions. Restriction digests were fractionated by agarose gel electrophoresis as described before.

\section{Phylogenetic analysis}

Sequence data were obtained from 21 Acari species (for GenBank accession numbers see Table 1) and two outgroup taxa (Limulus polyphemus [GenBank: NC 003057] and Locusta migratoria [Genbank: NC 001712]). Only mite species with a completely sequenced mt genome were selected. Alignments from all $\mathrm{mt}$ protein-coding genes were used in phylogenetic analysis. Amino acid sequences and nucleotide sequences were aligned by Clustal W [99] as implemented in BioEdit 7.0.1 [100]. The nucleotide alignment was generated based on the protein alignment using codon alignment. Ambiguously aligned parts were omitted from the analysis by making use of Gblocks 0.91b [105], with default block parameters except for changing "allowed gap positions" to "with half". Abascal et al. [106] recently presented evidence that some insects and ticks use a modified mitochondrial code, with AGG coding for lysine rather than serine as in the standard invertebrate mitochondrial code. As 10 out of 20 Acari species in our dataset are ticks all positions aligning to AGG codons in the final amino acid alignment were removed.

For the nucleotide alignments the "codons" option was used in Gblocks 0.91b [105]. Due to the results of a saturation analysis [107] on single codon positions, implemented in DAMBE 4.2.13 [108], third codon positions were eliminated from the nucleotide alignment. An incongruence length difference test (ILD-test) [78] as implemented in PAUP* (version 4.0b10; [109]) was used to assess congruence among gene partitions.

Model selection was done with ProtTest 1.4 [110] for amino acid sequences and with Modeltest 3.7 [111] for nucleotide sequences. According to the Akaike information criterion, the mtART $+\mathrm{G}+\mathrm{I}+\mathrm{F}$ model was optimum for phylogenetic analysis with amino acid alignments and the $\mathrm{GTR}+\mathrm{I}+\mathrm{G}$ model was optimal for analysis with nucleotide alignments.

Two different analyses were performed. (1) Maximum likelihood (ML) analysis was performed using Treefinder [112], bootstrapping with 1000 pseudoreplicates (2) Bayesian inference (BI) was done with MrBayes 3.1.2 [113]. As the mtART model is not implemented in the current version of MrBayes, the $m t R E V+G+I$ model was used for phylogenetic analysis with the amino acid alignment. Four chains ran for 1,000,000 generations, while tree sampling was done every 100 generations. Burnin was calculated when the average standard deviation of split frequencies had declined to $<0.01$. The remaining trees were used to calculate Bayesian posterior probabilities (BPP).

\section{Abbreviations}

12S-rRNA: small (12S) rRNA subunit (gene); 16S-rRNA: large (16S) rRNA subunit (gene); A: adenine; atp6 and 8 : ATPase subunit 6 and 8; BI: Bayesian inference; bp: base pairs; cox 1-3: cytochrome oxidase subunits I-III; $c y t B$ : cytochrome b; C: cytosine; D-arm: dihydrouridine-arm of a tRNA secondary structure; EST: expressed sequence tag; G: guanine; J-strand: majority strand; lnr: large non-coding 
region/control region; MP: maximum parsimony; ML: maximum likelihood; mRNA: messenger RNA; mt: mitochondrial; N-strand: minority strand; nad1-6 and nad $4 L$ : NADH dehydrogenase subunits $1-6$ and 4L; ORF: open reading frame; PCR: polymerase chain reaction; R.H.: relative humidity; rRNA: ribosomal RNA; T: thymine; T-arm: TYC-arm of a tRNA secondary structure; $\operatorname{trn} X$ (where $X$ is replaced by a one letter amino acid code for the corresponding amino acid, with $\mathrm{L}_{1}=\mathrm{CUN} ; \mathrm{L}_{2}=\mathrm{UUR}$; $\mathrm{S}_{1}=\mathrm{AGN}$; $\mathrm{S}_{2}=\mathrm{UCN}$ ), transfer RNA.

\section{Authors' contributions}

WD and TVL designed and conducted the experiments. WD and BV analysed data. WD wrote the manuscript. All authors read and approved the final manuscript.

\section{Additional material}

\section{Additional file 1}

Mitochondrial genome arrangements of 42 Chelicerata. Graphical linearisation of the mt genomes was done according to [32] (see Fig. 3). Corresponding GenBank accession numbers are between brackets. The position of $\mathrm{trnL}_{2}$ is grey shaded. Protein coding and $r R N A$ genes are abbreviated as in the Abbreviations section; tRNA genes are abbreviated using the one-letter amino acid code. Small non-coding regions (> 50bp) are indicated as gaps between genes. Braces accentuate the duplicated region in the $m t$ genome of $\mathrm{M}$. occidentalis.

Click here for file

[http://www.biomedcentral.com/content/supplementary/14712164-10-107-S1.jpeg]

\section{Additional file 2}

Across-strand ( $N$ and $J$ ) comparison of frequencies of codons ending with the same nucleotide. Values on the $\gamma$-axis represent the sum of Relative Synonymous Codon Usage (RSCU) values (Table 3) of codons ending with the same nucleotide across all codon families ( $x$-axis).

Click here for file

[http://www.biomedcentral.com/content/supplementary/1471-

2164-10-107-S2.jpeg]

\section{Additional file 3}

Average identity and similarity \% of mt proteins of $\mathrm{D}$. pteronyssinus. For each protein of D. pteronyssinus, a similarity and identity value was calculated with the corresponding protein of other Acari species (as listed in Table 1), using pairwise global alignment. The obtained values were used to calculate an average identity and similarity \% for each protein. Click here for file

[http://www.biomedcentral.com/content/supplementary/14712164-10-107-S3.jpeg]

\section{Additional file 4}

Start and stop codons of mt protein coding genes of complete $m t$ genomes of Acari.

Click here for file

[http://www.biomedcentral.com/content/supplementary/14712164-10-107-S4.xls]

\section{Additional file 5}

GenBank accession numbers and sequences of ESTs of D. pteronyssinus and $\mathrm{D}$. farinae covering the mt genome of $\mathrm{D}$. pteronyssinus. Click here for file

[http://www.biomedcentral.com/content/supplementary/14712164-10-107-S5.fas]

\section{Additional file 6}

Alignment of a mt genome fragment containing trnaM, trnaR and

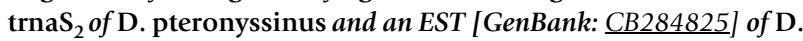
farinae. Anticodons and anticodon stems are red and green respectively. Acceptor-stems of $\operatorname{trnR}, \operatorname{trnM}$ and $\mathrm{trnS}_{2}$ are underlined. The stop codon of nad3 is grey shaded.

Click here for file

[http://www.biomedcentral.com/content/supplementary/14712164-10-107-S6.jpeg]

\section{Additional file 7}

Primers and their sequences used to characterise the D. pteronyssinus mt genome.

Click here for file

[http://www.biomedcentral.com/content/supplementary/1471-

2164-10-107-S7.doc]

\section{Additional file 8}

Input data for CREx.

Click here for file

[http://www.biomedcentral.com/content/supplementary/14712164-10-107-S8.xls]

\section{Acknowledgements}

TVL is a Postdoctoral Fellow of the Research Foundation Flanders (Belgium). BV had a postdoctoral grant from Ghent University (BOF0IP04105).

\section{References}

I. Harvey MS: The neglected cousins: What do we know about the smaller Arachnid orders? J Arachnol 2002, 30:357-372.

2. Acari. The Mites [http://tolweb.org/Acari/2554/1996.12.13]

3. Dunlop JA, Alberti G: The affinities of mites and ticks: a review. J Zool Syst Evol Res 2008, 46: I- I8.

4. O'Connor BM: Phylogenetic relationships among higher taxa in the Acariformes, with particular reference to the Astigmata. In Acarology VI Volume I. Edited by: Griffiths DA, Bowman CE. Chichester: Ellis-Horwood Ltd; 1984:19-27.

5. Spieksma FTM: Domestic mites from an acarologic perspectives. Allergy 1997, 52:360-368.

6. Voorhorst R, Spieksma FT, Varekamp H, Leupen MJ, Lyklema AW: House-dust mite (Dermatophagoides pteronyssinus) and allergens it produces. Identity with house-dust allergen. J Allergy 1967, 39:325-339.

7. van Bronswijk JEMA: House dust biology. The Netherlands: NIB Publishers; 1981.

8. Arlian LG, Platts-Mills TAE: The biology of dust mites and the remediation of mite allergens in allergic disease. J Allergy Clin Immunol 200I, 107:S406-S4I3.

9. Janson C, Anto J, Burney P, Chinn S, de Marco R, Heinrich J, Jarvis D, Kuenzli N, Leynaert B, Luczynska C, Neukirch F, Svanes C, Sunyer J, Wjst M: The European Community Respiratory Health Survey: what are the main results so far? Eur Respir J 200I, I 8:598-6II.

10. Dowton M, Castro LR, Austin AD: Mitochondrial gene rearrangements as phylogenetic characters in the invertebrates: 
the examination of genome 'morphology'. Invertebr Syst 2002, 16:345-356.

II. Boore JL, Macey JR, Medina M: Sequencing and comparing whole mitochondrial genomes of animals. In Molecular Evolution: Producing the Biochemical Data, Part B Volume 395. San Diego: Elsevier Academic Press Inc; 2005:3I I-348.

12. Boore $\mathrm{JL}$ : The use of genome-level characters for phylogenetic reconstruction. Trends Ecol Evol 2006, 21 :439-446.

13. Masta SE, Boore JL: Parallel evolution of truncated transfer RNA genes in arachnid mitochondrial genomes. Mol Biol Evol 2008, 25:949-959.

14. Curole JP, Kocher TD: Mitogenomics: digging deeper with complete mitochondrial genomes. Trends Ecol Evol 1999, 14:394-398.

15. Cameron SL, Miller KB, D'Haese CA, Whiting MF, Barker SC: Mitochondrial genome data alone are not enough to unambiguously resolve the relationships of Entognatha, Insecta and Crustacea sensu lato (Arthropoda). Cladistics 2004, 20:534-557.

16. Castro LR, Dowton M: Mitochondrial genomes in the Hymenoptera and their utility as phylogenetic markers. Syst Entomol 2007, 32:60-69.

17. Dekeyser MA: Acaricide mode of action. Pest Manag Sci 2005, 61:103-110.

18. Van Leeuwen T, Vanholme B, Van Pottelberge S, Van Nieuwenhuyse P, Nauen R, Tirry L, Denholm I: Mitochondrial heteroplasmy and the evolution of insecticide resistance: Non-Mendelian inheritance in action. Proc Natl Acad Sci USA 2008, 105:5980-5985.

19. NCBI - National Center For Biotechnology Information [http://www.ncbi.nlm.nih.gov/]

20. Wolstenholme DR: Animal mitochondrial DNA: structure and evolution. Int Rev Cytol 1992, 141:173-216.

21. Boore JL: Animal mitochondrial genomes. Nucleic Acids Res 1999, 27:1767-1780.

22. Domes K, Maraun M, Scheu S, Cameron SL: The complete mitochondrial genome of the sexual oribatid mite Steganacarus magnus: genome rearrangements and loss of tRNAs. BMC Genomics 2008, 9:532.

23. Jeyaprakash A, Hoy MA: The mitochondrial genome of the predatory mite Metaseiulus occidentalis (Arthropoda: Chelicerata: Acari: Phytoseiidae) is unexpectedly large and contains several novel features. Gene 2007, 39 1:264-274.

24. Shao RF, Mitani H, Barker SC, Takahashi M, Fukunaga M: Novel mitochondrial gene content and gene arrangement indicate illegitimate inter-mtDNA recombination in the chigger mite, Leptotrombidium pallidum. I Mol Evol 2005, 60:764-773.

25. Navajas M, Le Conte Y, Solignac M, Cros-Arteil S, Cornuet JM: The complete sequence of the mitochondrial genome of the honeybee ectoparasite mite Varroa destructor (Acari: Mesostigmata). Mol Biol Evol 2002, 19:23।3-23।7.

26. Shao RF, Barker SC, Mitani H, Aoki Y, Fukunaga M: Evolution of duplicate control regions in the mitochondrial genomes of metazoa: A case study with Australasian Ixodes ticks. Mol Biol Evol 2005, 22:620-629.

27. Mitani $\mathrm{H}$, Talbert A, Fukunaga M: New World relapsing fever Borrelia found in Ornithodoros porcinus ticks in central Tanzania. Microbiol Immunol 2004, 48:50I-505.

28. Gorrochotegui-Escalante N, Black WC: Amplifying whole insect genomes with multiple displacement amplification. Insect Mol Biol 2003, I 2: 195-200.

29. Howell N: Anomalous electrophoretic mobility of mouse mtDNA restriction fragments. Plasmid 1985, 14:93-96.

30. Staton JL, Daehler LL, Brown WM: Mitochondrial gene arrangement of the horseshoe crab Limulus polyphemus L: Conservation of major features among arthropod classes. Mol Biol Evol 1997, 14:867-874.

31. Lavrov DV, Boore JL, Brown WM: The complete mitochondrial DNA sequence of the horseshoe crab Limulus polyphemus. Mol Biol Evol 2000, 17:8|3-824.

32. Fahrein K, Talarico G, Braband A, Podsiadlowski L: The complete mitochondrial genome of Pseudocellus pearsei (Chelicerata: Ricinulei) and a comparison of mitochondrial gene rearrangements in Arachnida. BMC Genomics 2007, 8:386.

33. Lee YS, Oh J, Kim YU, Kim N, Yang S, Hwang UW: Mitome: dynamic and interactive database for comparative mitochondrial genomics in metazoan animals. Nucleic Acids Res 2008, 36:D938-D942.
34. Boore JL, Lavrov DV, Brown WM: Gene translocation links insects and crustaceans. Nature 1998, 392:667-668.

35. Berard S, Bergeron A, Chauve C, Paul C: Perfect sorting by reversals is not always difficult. IEEE/ACM Trans Comput Biol Bioinform 2007, 4:4-16.

36. Nardi F, Carapelli A, Fanciulli PP, Dallai R, Frati F: The complete mitochondrial DNA sequence of the basal Hexapod Tetrodontophora bielanensis: Evidence for heteroplasmy and tRNA translocations. Mol Biol Evol 200I, I 8: 1 293-I304.

37. Black WC, Roehrdanz RL: Mitochondrial gene order is not conserved in arthropods: Prostriate and metastriate tick mitochondrial genomes. Mol Biol Evol 1998, I5:1772-1785.

38. Shao R, Aoki Y, Mitani H, Tabuchi N, Barker SC, Fukunaga M: The mitochondrial genomes of soft ticks have an arrangement of genes that has remained unchanged for over $\mathbf{4 0 0}$ million years. Insect Mol Biol 2004, 13:21 9-224.

39. Sharp PM, Cowe E, Higgins DG, Shields DC, Wolfe KH, Wright F: Codon usage patterns in Escherichia coli, Bacillus subtilis, Saccharomyces cerevisiae, Schizosaccharomyces pombe, Drosophila melanogaster and Homo sapiens - A review on the considerable within species diversity. Nucleic Acids Res 1988, 16:8207-82II.

40. Hassanin A, Leger N, Deutsch J: Evidence for multiple reversals of asymmetric mutational constraints during the evolution of the mitochondrial genome of Metazoa, and consequences for phylogenetic inferences. Syst Biol 2005, 54:277-298.

41. Francino MP, Ochman H: Strand asymmetries in DNA evolution. Trends Genet 1997, 13:240-245.

42. Clayton DA: Replication and transcription of vertebrate mitochondrial DNA. Annu Rev Cell Biol I991, 7:453-478.

43. Yang MY, Bowmaker M, Reyes A, Vergani L, Angeli P, Gringeri E, Jacobs HT, Holt IJ: Biased incorporation of ribonucleotides on the mitochondrial L-strand accounts for apparent strandasymmetric DNA replication. Cell 2002, I I I:495-505.

44. Yasukawa T, Yang MY, Jacobs HT, Holt IJ: A bidirectional origin of replication maps to the major noncoding region of human mitochondrial DNA. Mol Cell 2005, 18:65I-662.

45. Brown TA, Cecconi C, Tkachuk AN, Bustamante C, Clayton DA: Replication of mitochondrial DNA occurs by strand displacement with alternative light-strand origins, not via a strandcoupled mechanism. Genes Dev 2005, 19:2466-2476.

46. Perna NT, Kocher TD: Patterns of nucleotide composition at fourfold degenerate sites of animal mitochondrial genomes. J Mol Evol 1995, 41:353-358.

47. Taanman JW: The mitochondrial genome: structure, transcription, translation and replication. Biochim Biophys Acta, Bioenerg 1999, 1410:103-123.

48. Carapelli A, Comandi S, Convey P, Nardi F, Frati F: The complete mitochondrial genome of the antartic springtail Cryptopygus antarcticus (Hexapoda: Collembola). BMC Genomics 2008, 9:315.

49. Gissi C, Pesole G: Transcript mapping and genome annotation of ascidian mtDNA using EST data. Genome Res 2003, 13:2203-2212.

50. Berthier F, Renaud M, Alziari S, Durand R: RNA mapping on Drosophila mitochondrial DNA - precursors and template strands. Nucleic Acids Res 1986, 14:4519-4533.

51. Ojala D, Montoya J, Attardi G: Transfer-RNA punctuation model of RNA processing in human mitochondria. Nature 1981, 290:470-474

52. Boore JL: The complete sequence of the mitochondrial genome of Nautilus macromphalus (Mollusca: Cephalopoda). BMC Genomics 2006, 7:182.

53. Wolstenholme DR, Macfarlane JL, Okimoto R, Clary DO, Wahleithner JA: Bizarre transfer-RNAs inferred from DNAsequences of mitochondrial genomes of nematode worms. Proc Natl Acad Sci USA 1987, 84: I 324-I 328.

54. Masta SE: Mitochondrial sequence evolution in spiders: Intraspecific variation in tRNAs lacking the T psi C arm. Mol Biol Evol 2000, 17:1091-I 100.

55. Ohtsuki T, Watanabe Y, Takemoto C, Kawai G, Ueda T, Kita K, Kojima S, Kaziro Y, Nyborg J, Watanabe K: An "elongated" translation elongation factor Tu for truncated tRNAs in nematode mitochondria. J Biol Chem 200I, 276:2157I-21577.

56. Arita M, Suematsu T, Osanai A, Inaba T, Kamiya H, Kita K, Sisido M, Watanabe Y, Ohtsuki T: An evolutionary 'intermediate state' of 
mitochondrial translation systems found in Trichinella species of parasitic nematodes: co-evolution of tRNA and EFTu. Nucleic Acids Res 2006, 34:529I-5299.

57. Ohtsuki T, Watanabe Y: T-armless tRNAs and elongated elongation factor Tu. IUBMB Life 2007, 59:68-75.

58. Cui P, Ji R, Ding F, Qi D, Gao HW, Meng H, Yu J, Hu SN, Zhang HP: A complete mitochondrial genome sequence of the wild two-humped camel (Camelus bactrianus ferus): an evolutionary history of camelidae. BMC Genomics 2007, 8:24I.

59. Davila S, Pinero D, Bustos P, Cevallos MA, Davila G: The mitochondrial genome sequence of the scorpion Centruroides limpidus (Karsch 1879) (Chelicerata; Arachnida). Gene 2005, 360:92-102.

60. Masta SE, Boore JL: The complete mitochondrial genome sequence of the spider Habronattus oregonensis reveals rearranged and extremely truncated tRNAs. Mol Biol Evol 2004, 21:893-902.

61. Lavrov DV, Brown WM, Boore JL: A novel type of RNA editing occurs in the mitochondrial tRNAs of the centipede Lithobius forficatus. Proc Natl Acad Sci USA 2000, 97:13738-13742.

62. Zhang DX, Hewitt GM: Insect mitochondrial control region: A review of its structure, evolution and usefulness in evolutionary studies. Biochem Syst Ecol 1997, 25:99-120.

63. Goldstein DB, Schlotterer C: Microsatellites: Evolution and Applications. USA: Oxford University Press; 1999

64. Cameron SL, Whiting MF: The complete mitochondrial genome of the tobacco hornworm, Manduca sexta, (Insecta: Lepidoptera: Sphingidae), and an examination of mitochondrial gene variability within butterflies and moths. Gene 2008, 408: $112-123$.

65. Yue GH, Liew WC, Orban L: The complete mitochondrial genome of a basal teleost, the Asian arowana (Scleropages formosus, Osteoglossidae). BMC Genomics 2006, 7:242.

66. Mayer F, Kerth G: Microsatellite evolution in the mitochondrial genome of Bechstein's bat (Myotis bechsteinii). J Mol Evol 2005, 61:408-416.

67. Zardoya R, Meyer A: Cloning and characterization of a microsatellite in the mitochondrial control region of the African side-necked turtle, Pelomedusa subrufa. Gene 1998 216: 149-153.

68. Arnason $U$, Johnsson E: The complete mitochondrial DNA sequence of the harbor seal, Phoca vitulina. I Mol Evol 1992, 34:493-505.

69. Arnason U, Gullberg A, Johnsson E, Ledje C: The nucleotide sequence of the mitochondrial DNA molecule of the gray seal Halichoerus grypus, and a comparison with mitochondrial sequences of other true seals. J Mol Evol I993, 37:323-330.

70. Hoelzel AR, Hancock JM, Dover GA. Generations of VNTRS and heteroplasmy by sequence turnover in the mitochondrial control region of 2 elephant seal species. J Mol Evol 1993, 37:190-197.

71. Saccone C, Pesole G, Sbisa E: The main regulatory region of mammalian mitochondrial DNA - Structure function model and evolutionary pattern. J Mol Evol I99I, 33:83-91.

72. Zardoya $R$, Meyer A: The complete nucleotide sequence of the mitochondrial genome of the lungfish (Protopterus dolloi) supports its phylogenetic position as a close relative of land vertebrates. Genetics 1996, 142: 1249-1263.

73. He Y, Jones J, Armstrong M, Lamberti F, Moens M: The mitochondrial genome of Xiphinema americanum sensu stricto (Nematoda: Enoplea): Considerable economization in the length and structural features of encoded genes. J Mol Evol 2005 61:819-833.

74. Shao RF, Barker SC, Mitani H, Takahashi M, Fukunaga M: Molecular mechanisms for the variation of mitochondrial gene content and gene arrangement among chigger mites of the genus Leptotrombidium (Acari: Acariformes). J Mol Evol 2006, 63:25I-26I.

75. De Rijk P, Robbrecht E, De Hoog S, Caers A, Peer Y Van de, De Wachter R: Database on the structure of large subunit RNA. Nucleic Acids Res 1999, 27: 174-178.

76. Peer Y Van de, Caers A, De Rijk P, De Wachter R: Database on the structure of small ribosomal subunit RNA. Nucleic Acids Res 1998, 26:179-182.

77. Yamazaki N, Ueshima R, Terrett JA, Yokobori S, Kaifu M, Segawa R, Kobayashi T, Numachi K, Ueda T, Nishikawa K, Watanabe K, Thomas
RH: Evolution of pulmonate gastropod mitochondrial genomes: Comparisons of gene organizations of Euhadra, Cepaea and Albinaria and implications of unusual tRNA secondary structures. Genetics 1997, 145:749-758.

78. Farris JS, Kallersjo $M$, Kluge $A G$, Bult $C$ : Constructing a significance test for incongruence. Syst Biol 1995, 44:570-572.

79. Cunningham $\mathrm{CW}$ : Can three incongruence tests predict when data should be combined? Mol Biol Evol 1997, I 4:733-740.

80. Dolphin K, Belshaw R, Orme CDL, Quicke DLJ: Noise and incongruence: Interpreting results of the incongruence length difference test. Mol Phylogenet Evol 2000, 17:401-406.

81. Yoder AD, Irwin JA, Payseur BA: Failure of the ILD to determine data combinability for slow loris phylogeny. Syst Biol 200I, 50:408-424.

82. Barker FK, Lutzoni FM: The utility of the incongruence length difference test. Syst Biol 2002, 5 1:625-637.

83. Dowton M, Austin AD: Increased congruence does not necessarily indicate increased phylogenetic accuracy - The behavior of the incongruence length difference test in mixedmodel analyses. Syst Biol 2002, 5 I:19-3I.

84. Hipp AL, Hall JC, Sytsma KJ: Congruence versus phylogenetic accuracy: Revisiting the incongruence length difference test. Syst Biol 2004, 53:8I-89.

85. Kluge AG: A concern for evidence and a phylogenetic hypothesis of relationships among Epicrates (Boidae, Serpentes). Syst Zool 1989, 38:7-25.

86. Felsenstein J: Cases in which parsimony or compatibility methods will be positvely misleading. Syst Zool I978, 27:40I-4I0.

87. Cunningham $\mathrm{CW}$, Zhu $\mathrm{H}$, Hillis DM: Best-fit maximum-likelihood models for phylogenetic inference: Empirical tests with known phylogenies. Evolution 1998, 52:978-987.

88. Barker SC, Murrell A: Phylogeny, evolution and historical zoogeography of ticks: a review of recent progress. Exp Appl Acarol 2002, 28:55-68.

89. Klompen H, Lekvelshvili M, Black WC: Phylogeny of parasitiform mites (Acari) based on rRNA. Mol Phylogenet Evol 2007, 43:936-95।.

90. Murrell A, Dobson SJ, Walter DE, Campbell NJH, Shao RF, Barker SC: Relationships among the three major lineages of the Acari (Arthropoda: Arachnida) inferred from small subunit rRNA: paraphyly of the parasitiformes with respect to the opilioacariformes and relative rates of nucleotide substitution. Invertebr Syst 2005, 19:383-389.

91. Miyamoto J, Ishii A, Sasa M: Successful method for mass-culture of house dust mite, Dermatophagoides pteronyssinus (Trouessart, 1897). Jpn J Exp Med 1975, 45: I33-138.

92. Kalpaklioglu AF, Ferizli AG, Misirligil Z, Demirel YS, Gurbuz L: The effectiveness of benzyl benzoate and different chemicals as acaricides. Allergy 1996, 5 I:164-170.

93. Bischoff E: Méthodes actuelles de quantification des acariens dans I'habitat. Rev Fr Allergol 1988, 28: I I 5-I22.

94. Hart B: Ecology and biology of allergenic mites. In Mites and Allergic disease Edited by: Guerin. Belgium: Groeninge Press; 1990:135-I52

95. Sambrook J, Russel D: Molecular Cloning: a Laboratory Manual 2nd edition. United states: Cold Spring Harbor Laboratory Press; 1987.

96. Rice P, Longden I, Bleasby A: EMBOSS: The European Molecular Biology Open Software Suite. Trends Genet 2000, 16:276-277.

97. Altschul SF, Madden TL, Schaffer AA, Zhang JH, Zhang Z, Miller W, Lipman DJ: Gapped BLAST and PSI-BLAST: a new generation of protein database search programs. Nucleic Acids Res 1997. 25:3389-3402.

98. Lowe TM, Eddy SR: tRNAscan-SE: A program for improved detection of transfer RNA genes in genomic sequence. Nucleic Acids Res 1997, 25:955-964.

99. Thompson JD, Higgins DG, Gibson TJ: CLUSTAL-W - Improving the sensitivity of progressive multiple sequence alignment through sequence weighting, position-specific gap penalties and weight matrix choice. Nucleic Acids Res 1994, 22:4673-4680.

100. Hall T: BioEdit: a user-friendly biological sequence alignmenteditor and analysis program for Windows $95 / 98 /$ NT. Nucleic Acids Symp Ser 1999, 41:95-98

I0I. Campanella JJ, Bitincka L, Smalley J: MatGAT: An application that generates similarity/identity matrices using protein or DNA sequences. BMC Bioinformatics 2003, 4:29. 
102. Bernt M, Merkle D, Ramsch K, Fritzsch G, Perseke M, Bernhard D, Schlegel M, Stadler PF, Middendorf M: CREx: inferring genomic rearrangements based on common intervals. Bioinformatics 2007, 23:2957-2958.

103. Zuker M: Mfold web server for nucleic acid folding and hybridization prediction. Nucleic Acids Res 2003, 31:3406-34I5.

104. De Rijk P, Wuyts J, De Wachter R: RnaViz 2: an improved representation of RNA secondary structure. Bioinformatics 2003, 19:299-300.

105. Castresana J: Selection of conserved blocks from multiple alignments for their use in phylogenetic analysis. Mol Biol Evol 2000, 1 7:540-552.

106. Abascal F, Posada D, Knight RD, Zardoya R: Parallel evolution of the genetic code in arthropod mitochondrial genomes. PLOS Biol 2006, 4:7II-7I8.

107. Xia XH, Xie Z, Salemi M, Chen L, Wang Y: An index of substitution saturation and its application. Mol Phylogenet Evol 2003, 26: I-7.

108. Xia X, Xie Z: DAMBE: Software package for data analysis in molecular biology and evolution. J Hered 200I, 92:37I-373.

109. Swofford DL: PAUP*. Phylogenetic Analysis Using Parsimony (*and Other Methods), version 4.0b I0. Sunderland, Massachusetts: Sinauer Asociates; 2003.

110. Abascal F, Zardoya R, Posada D: ProtTest: selection of best-fit models of protein evolution. Bioinformatics 2005, 21:2104-2105.

III. Posada D, Crandall KA: MODELTEST: testing the model of DNA substitution. Bioinformatics 1998, 14:817-8|8.

1 12. Jobb G, von Haeseler A, Strimmer K: TREEFINDER: a powerful graphical analysis environment for molecular phylogenetics. BMC Evol Biol 2004, 4: 18.

II3. Huelsenbeck JP, Ronquist F: MRBAYES: Bayesian inference of phylogenetic trees. Bioinformatics 200I, 17:754-755.

Publish with Bio Med Central and every scientist can read your work free of charge

"BioMed Central will be the most significant development for disseminating the results of biomedical research in our lifetime. "

Sir Paul Nurse, Cancer Research UK

Your research papers will be:

- available free of charge to the entire biomedical community

- peer reviewed and published immediately upon acceptance

- cited in PubMed and archived on PubMed Central

- yours - you keep the copyright

Submit your manuscript here:

http://www.biomedcentral.com/info/publishing_adv.asp
BioMedcentral 